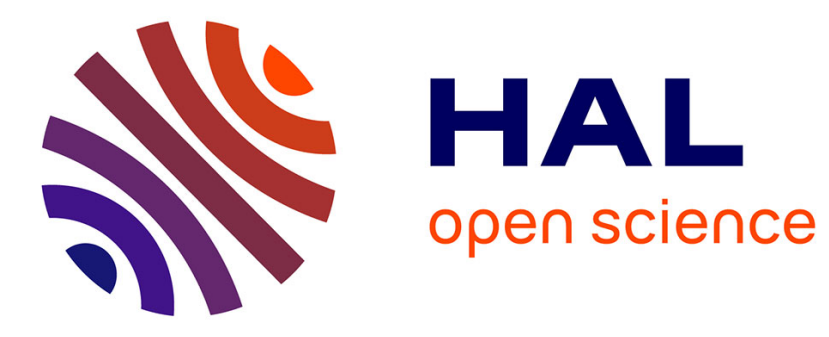

\title{
La France du Centre-Est (Auvergne, Bourgogne, Franche-Comté, Rhône-Alpes)
}

Philippe Barral, Pierre Nouvel, Franck Perrin, Matthieu Poux, Virginie Durand, Guillaume Maza, Patrick Porte, Catherine Bellon

\section{To cite this version:}

Philippe Barral, Pierre Nouvel, Franck Perrin, Matthieu Poux, Virginie Durand, et al.. La France du Centre-Est (Auvergne, Bourgogne, Franche-Comté, Rhône-Alpes). Gallia - Archéologie de la France antique, 2003, Cultes et sanctuaires en France à l'âge du Fer, 60, pp.139-168. 10.3406/galia.2003.3146 . hal-00670124

\section{HAL Id: hal-00670124 \\ https://hal.science/hal-00670124}

Submitted on 8 Jan 2020

HAL is a multi-disciplinary open access archive for the deposit and dissemination of scientific research documents, whether they are published or not. The documents may come from teaching and research institutions in France or abroad, or from public or private research centers.
L'archive ouverte pluridisciplinaire HAL, est destinée au dépôt et à la diffusion de documents scientifiques de niveau recherche, publiés ou non, émanant des établissements d'enseignement et de recherche français ou étrangers, des laboratoires publics ou privés.

\section{(이) $\$$}

Distributed under a Creative Commons Attribution - NonCommercial - NoDerivatives| 4.0 


\title{
LA FRANCE DU CENTRE-EsT
}

\section{(Auvergne, Bourgogne, Franche-Comté, Rhône-Alpes)}

\author{
Philippe Barral, Pierre Nouvel, Franck Perrin et Matthieu Poux \\ avec la participation de Virginie Durand, Guillaume MaZA, Patrick PorTE \\ et la collaboration de Catherine BELLON
}

\begin{abstract}
Mots-clés. Sanctuaires ruraux, prospection aérienne, Allobroges, Arvernes, Éduens, Sénons, Séquanes, dépôts, grottes, milieux humides, oppida, banquet, amphores, métal, territoire, faciès mobiliers.

Résumé. La région Centre-Est livre un ensemble numériquement encore faible, appartenant essentiellement aux derniers siècles avant le changement d'ère. Les découvertes nombreuses, anciennes ou récentes, de dépôts à caractère votif, illustrent la variété et la multiplicité des lieux cultuels (rivières, sources, grottes, habitats divers, etc.). Les recherches récentes attestent la réalité de lieux de cultes gaulois centraux ou ruraux organisés, souvent masqués par des sanctuaires d'époque impériale. Globalement, le Centre-Est semble se distinguer du "modèle belge » par une représentation plutôt faible de l'armement au profit des amphores vinaires, de la céramique, de linstrumentum domestique, de la parure, voire des monnaies... Les divinités gauloises honorées restent anonymes, faute de figurations et d'inscriptions.
\end{abstract}

Key-words. Rural sancluaries, aerial survey, Allobroges, Arverni, Aedui, Senones, Sequani, deposits, caves, river finds, oppida, banquet, wine amphorae, metal, territory, artefact facies.

Abstract. The amount of cult testimonies collected in this area is still thin and, for the most part, they are dated from the last centuries BC. The impressive finding, recent or previous, of votive deposits illustrates the varying kinds and multiplicity of sacred places (rivers, springs, caves, various settlements...). Recent investigations have provided conclusive evidence for Gallic central or rural organized cult sites, often sealed beneath Roman sanctuaries. On the whole, the central-eastern part of Gaul apparently differs from the Belgic pattern by the paucity of weapons compared to the frequency of wine amphorae, pottery, instrumentum domesticum, ornaments and even coins. Yet, Gaulish deities remain anonymous for lack of representations and inscriptions.

Schlagwörter. Ländliche Heiligtümer, Luftbildprospektion, Allobroger, Arverner, Häduer, Semnonen, Sequaner, Depots, Höhlen, Flußfunde, Oppida, Bankett, Weinamphoren, Metall, Territorium, Funde.

Zusammenfassung. Die Region liefert einen zahlenmäßig bisher noch kleinen Bestand an Befunden, die zur Hauptsache den letzten Jahrhunderten vor der Zeitenwende angehören. Zahlreiche alte und neue Entdeckungen von Weihefunden illustrieren die große Bandbreite der Kultorte (Flüsse, Quellen, Höhlen, gewisse Siedlungsplätze usw.). Die jüngeren Forschungen belegen auch die Existenz planmäßig errichteter gallischer Kultstätten an Zentralorten oder im ländlichen Bereich. Sie sind aber oft durch kaiserzeitliche Heiligtümer verdeckt. Insgesamt scheint sich die Region Centre-Est vom Beispiel der Belgica durch eine geringere Präsenz von Elementen der Bewaffnung zu unterscheiden. Dies schlägt zugunsten der Nachweise von Weinamphoren und sonstiger Gefäßkeramik, häuslichem Werkzeug und Gerät, Schmuck oder auch Münzen zu Buche. Weil es an entsprechenden Darstellungen und Inschriften mangelt, bleiben die hier verehrten gallischen Gottheiten jedoch anonym.zu Buche. Weil es an entsprechenden Darstellungen und Inschriften mangelt, bleiben die hier verehrten gallischen Gottheiten jedoch anonym.

Übersetzt vom Stefan WIRTH 


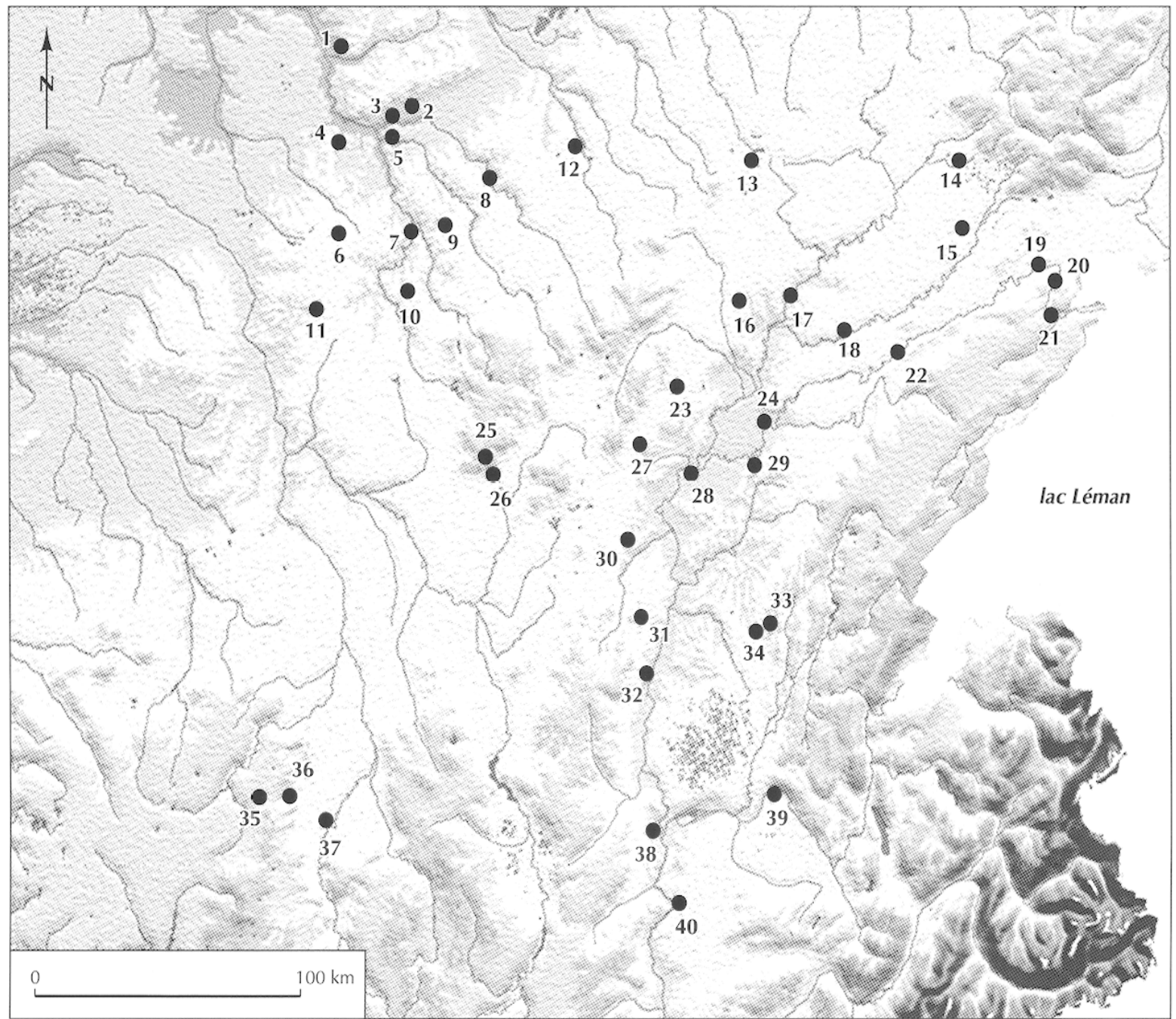

Fig. 75 - Carte de répartition des sites du Centre-Est de la France mentionnés dans le texte, voir tabl. IV (fond de carte P. Arcelin; DAO G. Devilder, CNRS).

Le Centre-Est réunit les quatre grandes régions limitrophes que sont l'Auvergne, la Bourgogne, la FrancheComté et Rhône-Alpes, soit plus d'une centaine de terroirs - de l'Auxerrois au Tricastin, du pays de Montbéliard aux monts du Cantal, du Chablais au bocage Bourbonnais, etc. - se distribuant autour du couloir fluvial Rhône-Saône, axe de circulation d'ampleur européenne (fig. 75 et tabl. IV). L'espace ainsi défini rassemble à la fin de l'âge du Fer quelques-uns des plus grands peuples de la Gaule (Éduens, Séquanes, Arvernes, Allobroges), excepté dans le sud-est où les données historiques permettent de situer une mosaïque de peuples disposant de territoires plus ou moins petits (Vellaves, Ségusiaves, Helviens, Voconces, etc.), voire très petits pour les peuples alpins.

Ce Centre-Est présente d'autres disparités puisque la majeure partie des peuples rhône-alpins (Ségusiaves et
Ambarres exceptés) perdent leur indépendance à partir de 121 avant J.-C. pour intégrer la province romaine de Transalpine. Les institutions sont tout aussi diverses avec, d'une part, le maintien de royautés (Arvernes) assez fragiles (Séquanes, Sénons) et, d'autre part, l'existence d'oligarchies sénatoriales (Éduens, Allobroges).

Compte tenu des remarques précédentes, on doit s'attendre à rencontrer des différences marquées pour ce qui concerne le domaine religieux et notamment pour les expressions matérielles des croyances. Rien, par exemple, ne vient nous éclairer sur l'extension du druidisme dont il faut croire qu'il dut être un des facteurs de l'unité des pratiques cultuelles que l'archéologie devrait pouvoir saisir : attesté chez les Éduens, il ne le fut certainement pas partout ailleurs dans cette Gaule du Centre-Est. Enfin, et cela n'est pas sans incidence sur le sujet traité ici, la recherche sur les 


\begin{tabular}{|c|c|c|c|c|c|}
\hline $\mathrm{N}^{\circ}$ & Commune & Lieu-dit & Département & $N^{0}$ notice & Pagination \\
\hline 1 & Fontaine-la-Gaillarde & La Grande Chaume & Yonne & 8 & $154-155$ \\
\hline 2 & Champlost & Foulon d'Avrolles & Yonne & 6 & 152-153 \\
\hline & Brienon-sur-Armançon & Fontaine de Thury & Yonne & \multirow{2}{*}{4} & \multirow{2}{*}{$150-152$} \\
\hline & Brienon-sur-Armançon & Champ de l'Areigne & Yonne & & \\
\hline 4 & Senan & Poirier Bourgeois & Yonne & 20 & 163 \\
\hline 5 & Ormoy & Souville & Yonne & 19 & 163 \\
\hline 6 & Fontenoy & Vallée de Solmet & Yonne & 9 & 155 \\
\hline 7 & Accolay & Passerelle Ruinée & Yonne & 1 & 150 \\
\hline 8 & Argentenay & Champ aux Os & Yonne & 2 & 150 \\
\hline 9 & Nitry & Champagne & Yonne & 16 & $160-162$ \\
\hline 10 & Saint-Père & & Yonne & - & - \\
\hline 11 & Menestreau & Saint-Sauveur & Nièvre & - & - \\
\hline 12 & Vix & Les Herbues & Côte-d'Or & - & - \\
\hline 13 & Langres & & Haute-Marne & - & - \\
\hline 14 & Luxeuil-les-Bains & & Haute-Saône & - & - \\
\hline 15 & Montjustin-et-Velotte & Le Fenis & Haute-Saône & - & - \\
\hline 16 & Mirebeau-sur-Bèze & La Fenotte & Côte-d'Or & 15 & 160 et 161 \\
\hline 17 & Apremont/Mantoche & & Hautc-Saônc & - & - \\
\hline 18 & Marnay & îles de Marnay & Haute-Saône & 14 & 160 \\
\hline 18 & \begin{tabular}{|l} 
Brussey \\
\end{tabular} & & Haute-Saône & - & - \\
\hline 19 & Bavans & & Doubs & - & $\begin{array}{ll}- \\
-\end{array}$ \\
\hline 20 & Mandeure & Le Clos du Château & Doubs & 13 & 159 \\
\hline 21 & Saint-Hippolyte & & Doubs & & \\
\hline & Chamesol & & Doubs & - & - \\
\hline 22 & Besançon & Arsenal & Doubs & - & - \\
\hline 23 & Nuits-Saint-Georges & Les Bolards & Côte-d'Or & 17 & 162 \\
\hline 24 & Champdivers & Ilion Chaudat & Jura & 5 & 152 \\
\hline 25 & Glux-en-Glenne & Sources de l'Yonne & Nièvre & - & - \\
\hline 26 & Glux-en-Glenne & Mont Beuvray & Nièvre & 10 & 155 \\
\hline 27 & Saint-Romain & Le Verger & Côte-d'Or & - & - \\
\hline 28 & Verdun-sur-le-Doubs & Le Petit-Chauvort & Saône-et-Loire & 21 & 163-164 \\
\hline 29 & Authumes & Le Tertre & Saône-et-Loire & 3 & 150 \\
\hline 30 & Chenôves & Creux Beurnichot & Saône-et-Loire & - & - \\
\hline 31 & Azé & & Saône-et-Loire & - & - \\
\hline 32 & Varennes-lès-Mâcon & & Saône-et-Loire & - & - \\
\hline 33 & Lains & & Jura & - & - \\
\hline 34 & La Balme-d'Épy & & Jura & - & - \\
\hline 35 & Orcines & & Puy-de-Dôme & 18 & $162-163$ \\
\hline 36 & Clermont-Ferrand & Le Brézet & Puv-de-Dôme & 7 & 153-154 \\
\hline 37 & Veyre-Monton & Puy de Corent & Puv-de-Dôme & 22 & 164-165 \\
\hline \begin{tabular}{|l|}
38 \\
\end{tabular} & Lyon & Le Verbe-Incarné & Rhône & 12 & 156-158 \\
\hline 39 & Hières-sur-Amby & Camp de Larina & Isère & 11 & $155-156$ \\
\hline 40 & Vienne & Sainte-Blandine & Isère & 23 & 165-168 \\
\hline
\end{tabular}

Tabl. IV - Tableau des sites mentionnés sur la carte figure 75.

âges du Fer présente de vives disparités suivant les régions ; ceci induit un évident déséquilibre géographique dans l'inventaire des lieux de culte des VIII ${ }^{\mathrm{e}} \mathrm{I}^{\mathrm{er}} \mathrm{s}$. avant J.-C. On constate aussi que les sanctuaires et les cultes du premier âge du Fer sont quasi inconnus, la majeure partie des faits religieux recensés ici appartenant à l'époque laténienne, surtout à ces deux derniers siècles. $\mathrm{Si}$, dans certaines régions, l'enquête s'est limitée à des révisions d'ensembles connus, voire à des reprises d'anciennes fouilles, des chantiers nouveaux ont permis de mettre en évidence le fait cultuel là où il n'existait pas auparavant. Le survol des sites gallo-romains, lorsqu'il est prolongé par des prospections de surface, s'est révélé fructueux pour l'identification de nouveaux gisements. Un certain nombre de sites potentiels de sanctuaires de l'âge du Fer ont été décelés par prospection aérienne (zone bourguignonne) mais n'ont encore fait l'objet d'aucune vérification.

Méthodologiquement, on constatera une certaine difficulté à mettre en évidence le fait cultuel à l'âge du Fer. Ceci s'explique sans doute par l'anonymat généralisé des découvertes: aucune mention de divinité ne peut être signalée, une situation qui tranche nettement avec celle des siècles postérieurs pour lesquels l'épigraphie fournit une multitude de théonymes gaulois, locaux et nationaux. Dans ces conditions - et notamment en l'absence de mobilier "sexué " tel l'armement - il est a fortiori impossible d'avoir des certitudes sur la nature masculine ou féminine des divinités honorées. Nombre de découvertes, fluviales et en grotte (où l'eau peut avoir joué un rôle), sont prises en compte en fonction d'une apparente " anormalité » des mobiliers: un critère différemment perçu ici selon les auteurs (voir le cas des dépôts monétaires, non retenus pour Rhône-Alpes). Pour les découvertes fluviales, on sait que bien des explications autres que cultuelles peuvent être avancées. Ailleurs, la destruction volontaire d'objets est un marqueur retenu, mais, cela peut paraitre paradoxal, la présence d'objets intacts l'est parfois tout autant. Il y a sans doute là une réflexion à développer dans l'avenir, en particulier à partir d'une définition d'une typologie des différents bris que l'on aimerait être fondée sur des obscrvations tangibles : l'apport des examens de laboratoire pourrait être précieux pour la compréhension des gestes cultuels ou supposés l'être (chauffe d'objets en métal, traces d'impact...). De même, il faut souhaiter le développement des études archéozoologiques à partir de séries provenant de tous types de contextes et non seulement d'ensembles supposés liés à des cultes.

Ces difficultés d'analyses expliquent qu'un site ou qu'une structure puissent être ici qualifiés de " cultuels " sans nécessairement l'être pour les inventeurs; cette remarque étant d'ailleurs particulièrement valable pour certaines découvertes « suspectes » en habitat. En revanche, il est un domaine où l'on sort de la spéculation. La présence de niveaux laténiens dans des sanctuaires gallo-romains (bien souvent anonymes) est assurément la meilleure approche pour distinguer le fait religieux gaulois et pour en reconnaitre les formes. Pour autant, nombre de sites recensés ici sont dépourvus de structures gallo-romaines, et parfois de toutes structures, et on ne doit pas les laisser de côté : on doit à ce propos espérer beaucoup de la révision de collections de ces niveaux récents d'occupation en grotte et de la découverte de nouveaux sites. Comme on le voit, le volet Centre-Fst de ce dossier sur les cultes et les sanctuaires de l'âge du Fer est l'occasion d'un début de réflexion 
sur - il faut le rappeler - des régions sans tradition de recherche. À partir d'un corpus volontairement large, quelques observations peuvent être énumérées: l'ancienneté de certains sites ; l'importance du nombre de lieux de cultes protohistoriques fonctionnant jusqu'à l'époque galloromaine (peut-être avec des hiatus imperceptibles dans l'état des connaissances); la part globalement faible occupée par l'armement (on pensera notamment à Mandeure ou Vienne) ; les différences régionales portant sur la représentation des amphores vinaires, surabondantes ici, quasi absentes là ; les indices de pratiques cultuelles plus privées que publiques; l'existence à peine entrevue des cultes funéraires.

\section{F. PLRRIN}

\section{LA BOURGOGNE}

Pour le premier âge du Fer, la découverte d'un sanctuaire probablement dédié à un culte héroïque et de statues en pierre, à près de $200 \mathrm{~m}$ de la tombe de Vix, constitue un apport majeur à la question des lieux cultuels anciens (Chaume et al., 2000a et b; Chaume, 2001; Chaume, Reinhard, à paraître). Pour le second âge du Fer, une étude récente sur l'occupation du territoire éduen dresse l'inventaire des lieux de culte les plus probables; outre Bibracte, on peut citer Saint-Sauveur à Menestreau, Sources de l'Yonne à Glux-en-Glenne, Varennes-lès-Mâcon et Azé (Barral, Guillaumet, 2000). La majeure partie des données nouvelles concerne le département de l'Yonne dans lequel prospections et révisions des collections modifient sensiblement la perception de cette région.

En ce qui concerne les sanctuaires stricto sensu, une gradation existe entre de petits temples ruraux, dont les caractéristiques architecturales comme les dépôts d'offrandes apparaissent relativement modestes (exemples icaunais), et de grands sanctuaires, comme celui de Mirebeau-sur-Bèze, que les structures et les dépôts mis au jour, mais aussi la localisation et la chronologie du site caractérisent comme un lieu cultuel majeur (voir infra notice 15, p. 160 et 161 ).

Dans l'espace bourguignon - franc-comtois, le début de ces grands sanctuaires (Mirebeau-sur-Bèze et Mandeure) semble pouvoir être situé à la fin du IVe-début du III's. avant J.-C. On notera que des sanctuaires laténiens et galloromains de moindre importance, tel que Menestreau, fournissent également des indices d'occupation remontant à La Tène ancienne (Garmier, Bouthier dir., 1996). Dans un nombre de cas significatifs, l'association sanctuairehabitat groupé ouvert, ou oppidum, est bien attestée (NuitsSaint-Georges, Varennes-lès-Mâcon, Mont Beuvray,
Besançon, Langres, Mandeure...), ce qui constitue un argument en faveur du rôle des sanctuaires dans la dynamique de proto-urbanisation. Cette forte articulation sanctuaire-habitat aggloméré peut également être discernée dans les rythmes de développement, les ruptures et continuités majeures qui concernent les deux catégories de sites, à partir des avancées de recherches récentes, encore inédites, sur plusieurs sites de l'espace bourguignon - franccomtois : Verdun-sur-le Doubs, Mirebeau-sur-Bèze, Mandeure, Langres (Joly, 2001), Besançon (Vaxelaire, Barral, 2003).

Concernant les milieux fluviaux, les découvertes d'objets sont particulièrement abondantes dans la Saône (Bonnamour, 1984, 1987). Pour le premier âge du Fer, il semble que la présence de vaisselle et d'armes puisse s'expliquer, au moins dans certains cas, par la destruction de nécropoles tumulaires implantées en bordure du fleuve ; en revanche, l'abondance des découvertes du second âge du Fer incite à envisager de véritables dépôts: ainsi on dénombre une centaine de lances et d'épées dans leur fourreau, une vingtaine de broches à rôtir, des dizaines de chaudrons, des outils (haches et faucilles), des entraves, etc. (Guillaumet, 2000; Dumont, 2002).

Quelques découvertes en grotte, toutes situées dans l'est du territoire éduen, semblent devoir être interprétées comme des dépôts votifs (Barral, Guillaumet, 2000, p. 67). Outre les dépôts de fibules des sources de la Douix (transition Hallstatt D3-La Tène A), c'est le cas notamment à Azé (La Tène D) ainsi qu'à Chenôves, une cavité dans laquelle une trentaine de statères en or figurent aux côtés des restes d'une douzaine d'individus (La Tène C2-D1) (Brunaux, 1986, p. 112-113), et sans doute également à Saint-Romain (Grappin, 1985). Ces faits cultuels relatifs aux grottes, attribuables à la fin de l'âge du Fer, sont certainement sous-évalués en Bourgogne, faute d'une recherche spécifique. Ils sont naturellement à rapprocher des exemples mis en évidence dans le massif jurassien (côtés français et suisse, voir infra), beaucoup plus nombreux semble-t-il, mais il est vrai que le contexte géologique y est également plus favorable, de façon générale.

Les manifestations cultuelles dans les habitats, non strictement liées à un sanctuaire, sont difficiles à mettre en évidence mais n'en existent pas moins comme le montrent plusieurs exemples, évoqués ci-dessous: Verdun-surle-Doubs (voir infra notice 21, p. 163-164), Mont Beuvray (notice 10, p. 155) et Authumes (notice 3, p. 150), où un ensemble d'objets ou une structure particulière posent la question de l'existence de pratiques rituelles ou de gestes votifs dans un contexte qui n'est pas strictement celui d'un temple ou d'une enceinte cultuelle. 


\section{LES SANCTUAIRES LATÉNIENS DANS LE NORD DE LA BOURGOGNE}

L'étude des lieux de culte fréquentés au cours du second âge du Fer pâtit, dans le nord de la Bourgogne et dans le département de l'Yonne en particulier, du manque de recherches récentes autant que de fouilles exhaustives. La synthèse publiée par J.-P. Delor et C. Rolley en 1989 ne reconnaissait ainsi qu'un seul sanctuaire laténien identifié avec certitude : Fontaine-la-Gaillarde (Delor, Rolley, 1989 et infra notice 8 , p. 154-155). Les découvertes récentes, en partie liées au développement des prospections aériennes et terrestres au cours des années 1990, permettent cependant de fournir un certain nombre d'informations inédites de première main. Sur trente lieux de culte antiques identifiés, seuls dix ont livré des indices de fréquentations antérieures au I ${ }^{\text {er }}$ s. après J.C. Il convient cependant de souligner l'aspect lacunaire et inégal des informations disponibles qui limitent la portée de leur étude comparée.

Parmi ces divers sanctuaires, seule une faible part a fait l'objet d'études de terrain récentes, postérieures aux années 1950. Le reste du corpus n'est documenté qu'à travers les prospections terrestres, aériennes ou les fouilles anciennes.

D'autres ont fait l'objet de fouilles dont le caractère ancien des études, l'aspect lacunaire des fouilles ou l'absence de conservation du matériel ne permettent pas de certifier ou d'infirmer leur fréquentation à l'époque laténienne. Le cas des sanctuaires de Montmarte à Vault-deLugny et du Buisson des Cochons à Crain est particulièrement représentatif. Là, les fouilles n'ont touché que les niveaux antiques superficiels mais la présence de structures plus anciennes n'est pas à exclure. Le site des FontainesSalées à Saint-Père est encore plus problématique. $S$ 'il est certain qu'il possède un indéniable caractère cultuel à l'époque antique, marqué par la présence d'ex voto médicaux, d'un bassin à offrandes monétaires et d'aménagements caractéristiques, il faut cependant noter l'absence de fanum dans l'espace fouillé ainsi que de matériel laténien dans les collections du musée municipal de Saint-Père. La relecture de la très abondante documentation ancienne $a$ néanmoins permis de localiser, au sud des bâtiments dégagés, une zone sondée en 1934 qui a fourni un certain nombre de monnaies gauloises et différents vestiges céramiques. Il faut donc supposer que la zone proprement cultuelle, fréquentée dès l'époque laténienne, du complexe des Fontaines-Salées reste à dégager et à étudier (voir SaintPère et Foissy-lès-Vézelay, in Delor dir., 2002).

C'est donc au développement des opérations de terrain, en particulier des prospections aériennes et terrestres liées à deux programmes de prospections-inventaires - dans le centre-nord du département sous la direction de J.-P. Delor entre 1988 et 1997 et dans la région entre les vallées de la Cure et du Serein, sous la direction de B. Poitout en cours depuis 1997 - que l'on doit l'essentiel des informations présentées ici, en dehors de la fouille du site de Fontaine-laGaillarde menée par J.-P. Sarazin. Ces méthodes de collecte surreprésentent cependant les zones biens prospectées (confluent Yonne-Armançon, vallées de l'Yonne et de la Cure) (Nouvel, 1995) où les terrains sont bien adaptés aux méthodes de prospections aériennes, aux dépens des zones de plateaux calcaires et, a fortiori, des espaces en pâture du massif du Morvan (région d'Avallon) et de la Puisaye.

Nous nous bornerons ici à présenter les gisements qui, malgré de très nombreuses lacunes, fournissent les indices d'une fréquentation antérieure à notre ère (voir infra notices $2,4,6,8,9,16,19$ et 20 ).

Malgré la faiblesse du corpus, quelques caractéristiques communes peuvent être dégagées. Tout d'abord la rémanence des découvertes monétaires, qui sont souvent les indices principaux pour déterminer le caractère cultuel. En second lieu, il faut remarquer qu'aucun des gisements identifiés ne présente de déposition d'armes caractéristiques. Cette lacune est probablement imputable à la nature très incomplète des recherches. Enfin, les quelques sites qui fournissent des indices de leur organisation interne (Fontaine-laGaillarde, Accolay, Nitry) à La Tène finale montrent de façon constante la présence d'enceintes fossoyées quadrangulaires de faible taille (de l'ordre dc $7 \mathrm{~m}$ dc côtć) qui semblent constituer le centre des pratiques cultuelles.

Leur localisation ne montre pas de spécificité particulière. Ils peuvent se trouver autant dans les vallées principales (Accolay, Ormoy, Argentenay), que dans des vallées secondaires ou sèches (Fontaine de Thury à Brienon-surArmançon, Champlost, Fontenoy) ou encore sur des plateaux (Fontaine-la-Gaillarde, Champ de l'Areigne à Brienon-sur-Armançon, Nitry). La proximité d'une source est loin d'être un caractère général, bien au contraire, deux seulement semblent structurés autour de points d'eau (Ormoy et Fontaine de Thury à Brienon-sur-Armançon).

D'autre part, la plupart d'entre eux apparaissent isolés, loin des centres de peuplement et des voies de communications, mis à part Champlost et Senan.

La permanence des lieux de culte, illustrée par la superposition exacte des structures laténiennes de Nitry et des aménagements gallo-romains, apparaît comme une constante dans l'état actuel de nos connaissances. Fontainela-Gaillarde doit être considéré comme un unicum, en raison de la proximité d'une nécropole contemporaine et d'une courte période de fréquentation. L'ensemble des autres lieux de culte connaît des réoccupations et des reconstructions, parfois importantes, au cours des premiers siècles de notre ère. 
Ce rapide tour d'horizon montre l'ampleur des lacunes accumulées dans ces régions et la nécessité d'études et de travaux archéologiques nouveaux. L'exemple des informations fournies par les fouilles réalisées à Nitry illustre cette nécessité et se veut l'exemple de la dynamisation des études laténiennes dans le département de l'Yonne.

P. BARRAL et P. NoUvel

\section{LA FRANCHE-COMTÉ}

\section{LE DÉPARTEMENT DU JURA}

Un certain nombre de découvertes monétaires anciennes, nombreuses dans le Jura, sont à interpréter dans le sens de dépôts à caractère votif, particulièrement dans le cas de trouvailles récurrentes dans un même lieu et plus encore lorsque l'on a affaire à de véritables trésors, comme à Chaussenans, Chavéria, Cramans, Lains, La Marre et Plasne. Dans deux cas au moins, il n'y a pas d'ambiguité possible à La Balme-d'Épy et Lains : association de statères et quarts de statères et de bracelets, évoquant clairement les dépôts de type Saint-Louis. Au titre des dépôts votifs peut être évoqué également un site où la relation avec l'eau est clairement identifiée, Champdivers, en bordure du Doubs (voir infra notice 5, p. 152). Le corpus des objets récoltés à Champdivers est tout à fait analogue à celui des sites cultuels les plus importants de la Saône. Les trouvailles de Champdivers apparaissent faussement isolées. Le Doubs peut certainement être placé sur le même plan que la Saône, dont les découvertes de passages à gué sont désormais bien connues et répertoriées (voir en dernier lieu : Bonnamour, 2000 ; Guillaumet, 2000 ; Dumont, 2002).

On manque souvent d'informations concernant les contextes de découvertes de mobiliers à caractère votif. Outre, les rivières et lieux humides (sources, marécages) qui ont déjà été évoqués, les grottes méritent une mention particulière. En effet, les occupations de grottes à La Tène moyenne ou finale, bien attestées dans le département du Jura (La Balme-d’Épy, Baume-les-Messieurs, Montagna-leReconduit, Les Planches-près-Arbois), comme de façon générale dans tout le massif jurassien, posent un problème d'interprétation (Kaenel, 1991 ; Dard, 1998). On hésite pour les trouvailles de la fin de l'âge du Fer entre diverses hypothèses: occupations temporaires (grotte refuge), pratiques cultuelles (grotte sanctuaire), voire, dans certains cas, aménagements funéraires (grotte sépulcrale). Cette dernière fonction semble attestée par la découverte récente de Geraise. La fréquence particulière des monnaies, parfois sous forme de véritables dépôts, la forte représentation des objets de parure, fibules, bracelets et perles en verre, sont des traits récurrents qui tissent selon nous des liens avec les dépôts d'offrandes des sanctuaires celtiques, voir l'exemple proche de Mirebeau-sur-Bèze (Barral, Guillaumet, 1994). Toutefois, il est difficile d'être pleinement affirmatif pour les cas jurassiens, en dehors de La Balme-d'Épy, où un dépôt d'une dizaine de monnaies d'argent constitue un argument de poids en faveur de l'hypothèse cultuelle (à comparer avec les dépôts de Chenôves en Saône-et-Loire et SaintRomain en Côte-d'Or).

\section{LE DÉPARTEMENT DE LA HAUTE-SAÔNE}

Pour la Haute-Saône, les données sont plus faibles que pour le département du Jura, et de nature très comparable (Barral, 2002 ; Faure-Brac dir., 2002).

Un groupe cohérent est identifiable avec les trouvailles effectuées à proximité ou à l'emplacement même de passages à gué. Trois gisements principaux peuvent être signalés : le premier sur le cours de la Saône (Apremont, Mantoche), les deux autres sur l'Ognon (Brussey et Marnay). La présence d'armes (épées, fers de lance) est tout à fait caractéristique de ce type de dépôt. La série de mobilier la plus conséquente provient des Îles de Marnay (voir infra notice 14, p. 160). On notera des analogies remarquables entre les trouvailles de ce site et celles de gisements de la moyenne vallćc dc la Saônc et de la basse vallée du Doubs (Champdivers, en particulier). On manque cependant, pour ce matériel recueilli au cours de dragages, d'indications sur les contextes de découvertes et la taphonomie des dépôts qui permettraient de préciser la (ou les) fonction(s) de ce type de site.

Une seconde série de découvertes peut être reliée à la catégorie assez nombreuse des sanctuaires indigènes. Il existe une gradation entre des sites relativement bien documentés, tel Montjustin-et-Velotte, et des sites dont l'identification est hypothétique et ne repose que sur des indices matériels, telles que l'abondance de numéraire, la présence de monnaies en or, de rouelles, auxquels s'ajoutent parfois de maigres observations topographiques ou autres : à Avrigney-Virey, Beaujeu, Esboz-Brest, Francalmont, Fresse, Montot, Vars et Vregille (Faure-Brac dir., 2002). On notera que la plupart de ces sites de sanctuaires potentiels occupent une hauteur ou se trouvent en position dominante. La continuité de l'occupation entre La Tène finale et le HautEmpire semble avérée dans la plupart des cas.

Enfin, deux sources auxquelles on attribue des vertus thermales (Luxeuil-les-Bains et Visoncourt), aménagées à l'époque romaine, ont livré des monnaics gauloises, ce qui peut être interprété comme l'indice d'une fonction votive à. La Tène finale. À Luxeuil-les-Bains, l'existence d'un sanc- 
tuaire de source pourrait avoir joué un rôle dans l'émergence de l'agglomération gallo-romaine.

\section{LE DÉPARTEMENT DU DOUBS}

Les remarques faites plus haut, tant en ce qui concerne les trouvailles en grotte que les découvertes réalisées dans le lit de rivières, sont également pertinentes pour ce département. Au titre des grottes, pour lesquelles des dépôts à caractère votif peuvent être évoqués, sont à citer particulièrement les sites de Chamesol de La Tène $\mathrm{D}$ (monnaies, perles annulaires et bracelet en verre, fibules de Nauheim) et de Bavans (céramique, bracelets en verre, fibules de Nauheim, support de cruche en bronze, pointes de flèche en fer) (Joan, à paraître). Deux sanctuaires laténiens importants, associés à des agglomérations, méritent d'être mentionnés, ceux de l'Arsenal à Besançon (Lagrange, 1992) et de Mandeure (voir infra notice 13, p. 159). Outre les rapprochements évidents que l'on peut faire entre ces deux sites d'agglomération du point de vue de leur implantation, dans un méandre du Doubs, ces deux sanctuaires possèdent en commun la particularité de présenter, à l'époque romaine, un grand péribole circulaire. Si l'on sait peu de choses sur celui de Besançon, en revanche, une étude en cours des trouvailles réalisées à la fin du XIX ${ }^{e}$ s., dispersées dans plusieurs musées et en grande partie inédites, permel de réévaluer le sanctuaire de Mandeure.

\section{P. BARRAL}

\section{L'AUVERGNE}

L'Auvergne administrative, une fraction du territoire historique des Arvernes, ne fait état que de trois sanctuaires stricto sensu (présence d'un temenos, d'un bâtiment cultuel et de dépôts d'offrandes caractéristiques), mais ceci est un état provisoire au vu du caractère récent des découvertes. En outre, ils sont liés à deux agglomérations majeures identifiées à la capitale du territoire arverne, aux $\mathrm{II}^{\mathrm{e}} \mathrm{s}$. et $\mathrm{I}^{\mathrm{er}} \mathrm{s}$. avant J.-C. : Aulnat-Le Brézet à Clermont-Ferrand et l'oppidum du puy de Corent. Le troisième d'entre eux, Orcines, coïncide avec l'emplacement du grand sanctuaire de Mercure érigé au ${ }^{\mathrm{er}}$ s. après J.-C. au sommet du puy de Dôme. Les avancées récentes dans le bassin clermontois concernent surtout les habitats : elles y ont mis en évidence de nombreux dépôts cultuels, dont l'étude pourrait déboucher sur l'identification de nouveaux lieux de culte.

Le sanctuaire d'Orcines doit à sa seule situation et à la monumentalité de ses vestiges d'époque romaine d'être considéré par certains comme le sanctuaire principal de la cité (voir infra notice 18, p. 162-163). Le mobilier recueilli anciennement et, en particulier, la présence d'armement mutilé y témoignent d'une activité cultuelle qui pourrait remonter jusqu'à La Tène ancienne. Sa difficulté d'accès, sa surface limitée et l'absence de toute agglomération permanente à son sommet le rendaient néanmoins peu adapté à des rassemblements importants et réguliers. Rien n'exclut qu'il n'ait été, jusqu'à la conquête, qu'un simple lieu de consécration fréquenté épisodiquement plutôt qu'un lieu de culte actif à vocation politique et juridique, occupé de façon continue.

Le territoire arverne disposait, à cet effet, d'autres sites plus proches des agglomérations principales, pourvus de tout l'espace nécessaire et d'aménagements ad hoc.

Le sanctuaire du puy de Corent en offre la meilleure illustration. Sa conception architecturale, classique, a été précisée en 2001 et 2002 (voir infra notice 22, p. 164-165). La masse et la dispersion des offrandes laissent à penser que sa surface totale excédait de loin les limites fixées à l'époque romaine. La présence d'armes en quantités non négligeables, triées par catégories fonctionnelles et volontairement mutilées, établit un lien avec les sanctuaires guerriers de Gaule belgique mais, comme dans d'autres sanctuaires de Gaule centrale et méridionale, le faciès des offrandes inclut surtout des restes d'animaux consommés et de céramiques, en particulier d'amphores vinaires. Il semble que le site ait eu pour fonction première d'hébcrgcr dc grands rassemblements festifs, assortis de sacrifices et de libations. La dimension politique assignée à ces manifestations s'illustre également par l'intense activité monétaire attestée dans son enceinte ou ses abords immédiats: plusieurs centaines de pièces en argent, en bronze et autant de substituts céramiques (jetons) sont conformes à ce que l'on connaît d'autres sanctuaires précédant la conquête romaine.

Le site du Brézet s'apparente étroitement au précédent, tant du point de vue de sa situation que de ses aménagements (voir infra notice 7, p. 153-154). Cette parenté se traduit aussi par les nombreux dépôts à caractère alimentaire et libatoire enfouis à sa périphérie : puits et fosses, comblés d'un mobilier sélectionné et organisé, où amphores, faune consommée et meules prédominent nettement. La vocation cultuelle de ce site est confortée par la découverte au sommet de l'un des puits d'une inhumation de cheval, associée à un dépôt métallique. Les interventions successives effectuées dans le secteur marécageux jouxtant le site de Grandaillat à Aulnat ont livré d'autres vestiges de même nature, qui soulignent l'étendue d'une zone cultuelle de plusieurs hectares.

Ces nouvelles découvertes peuvent être rapprochées de la mention par Strabon d'un grand sanctuaire situé à l'emplacement de la capitale des Arvernes, dont le nom romain 
(Augustonemetum) trahit une origine religieuse. L'hypothèse communément admise d'un transfert de la capitale arverne sur l'oppidum du puy de Corent, à la charnière des $\mathrm{II}^{\mathrm{e}}-\mathrm{I}^{\mathrm{er}} \mathbf{s}$. avant J.-C., trouve confirmation dans l'unité architecturale qui se dégage des deux sites. L'enclos de Corent constitue la réplique exacte, en plus grand, du bâtiment du Brézet, qui le précède d'une à deux générations. Ce lien de filiation peut être interprété dans le sens d'une translation ou d'une extension du rôle politico-religieux assigné aux principaux chefs-lieux du territoire arverne. Il est révélateur, à cet égard, d'observer que les deux sites sont précédés d'une séquence d'occupation remontant au Néolithique et à l'âge du Bronze (dépôts animaux ou céramiques dont la nature suggère l'existence d'une tradition cultuelle plus ancienne). Le fait que tous deux aient été réoccupés à l'époque romaine par un fanum est tout aussi significatif.

Un élément nouveau réside peut-être au pied de l'oppidum de Gondole, au sud-ouest de Clermont-Ferrand. Des travaux réalisés en 1825 au lieu-dit Les Piaux y avaient mis au jour de très nombreux ossements de squelettes humains et de chevaux, interprétés alors comme ceux d'une nécropole ou les vestiges de la bataille de Gergovie. En 2002, un sondage y a mis au jour une grande fosse rectangulaire, au fond de laquelle gisaient huit squelettes de petits chevaux mâles soigneusement alignés sur le flanc droit, en deux rangs superposés. À leur côté, dans la même disposition, gisaient huit défunts, tous adultes excepté un adolescent d'environ 15 ans (Cabezuelo, 2002). Cette découverte, qui présente d'étroites similitudes avec la fosse aux chevaux du sanctuaire de Vertault en Côte-d'Or, a été suivie par celle, proche, de cinq autres fosses quadrangulaires contenant uniquement des restes de chevaux.

Il semble néanmoins, au vu des données actuelles, que la consécration des dépouilles sacrificielles et guerrières jouait un rôle marginal dans l'activité religieuse du territoire arverne. Les aménagements et les dépôts qu'elle mettait en œuvre rappellent d'autres rituels, spécifiques aux sanctuaires du sud de la Loire. Amphores vinaires et ossements d'animaux consommës ä titre collectif (moutons et porcs), destinés aux festins et libations. De telles cérémonies n'ont rien d'imaginaire puisqu'elles sont précisément évoquées par Poseidonios à propos des Arvernes, lors de son séjour en Gaule au I ${ }^{\text {cr }}$ s. avant J.-C. (Athénée, IV, 36) : les festins organisés par le chef arverne Luernios à des fins politiciennes, qui faisait ériger de grands enclos emplis de cuves de vin (puits à cuvelage en bois ?), ponctués de grandes distributions de pièces d'or et d'argent. Ces festins se déroulaient, à Corent comme au Brézet, en périphérie de grands bâtiments rectangulaires réservés à l'activité rituelle stricto sensu, c'est-à-dire aux sacrifices et aux libations précédant le repas collectif, matérialisés par des structures spécifiques et complémentaires sur le plan liturgique: pierre d'autel utilisée pour la mise à mort des animaux, doublée d'un " autel creux ", destiné à recueillir le sang des victimes et le vin des amphores.

Ces deux lieux de culte arvernes s'inscrivent, sur un plan plus général, dans la mouvance des grands " sanctuaires à libations » de la Gaule du Sud-Ouest et du Centre-Est. Leurs aménagements et leurs dépôts établissent la synthèse entre des phénomènes aussi différents et géographiquement éloignés que les "puits à offrandes " de Toulouse, d'Agen et de Rodez, les "fossés à amphores " de Lyon ou d'Aix et le grand enclos d'Arnac-la-Poste dans le Limousin. Ils sont la manifestation de rites festifs et libatoires qui possèdent des ramifications plus au nord et à l'ouest, du sanctuaire de Muron en Charente-Maritime à celui de Naix-aux-Forges dans la Meuse (Poux, 2000a). Leur répartition dessine, du sud de la Loire à l'axe rhodanien en passant par le Massif central, une communauté de pratiques qui tranche nettement avec les rites sacrificiels et guerriers en vigueur en Gaule belgique. Cette situation renvoie peut-être, en partie, à des différences d'ordre chronologique : l'hypothèse d'un abandon progressif des rites guerriers pour des rites alimentaires à la fin de La Tène moyenne constitue une autre alternative, eu égard à la datation relativement tardive des sanctuaires du Brézet, de Corent et de leurs homologues des $\mathrm{II}^{\mathrm{c}}$ et $\mathrm{I}^{\mathrm{er}} \mathrm{s}$. avant J.-C. La fréquence des offrandes céramiques sur lc sanctuairc du puy de Dôme, qui compte également une part importante d'amphores vinaires républicaines, témoigne peut-être d'une évolution analogue.

Certains auteurs y ont vu, à tort, l'expression d'une logique "économique " opposée à l'idéologie guerrière traditionnelle, une forme d'offrandes originale liée à la romanisation plus précoce et à l'essor du commerce dans cette partie de la Gaule: amphores, céramiques et monnaies, perçues comme les attributs d'une divinité topique protectrice du commerce arverne qui aurait été assimilée, après la conquête, au Mercure gréco-romain (Mercurius Dumias). Le culte qui lui était dédié et la fameuse mention de Pline, situant en territoire arverne une grande statue en bronze à son effigie, ne concernent que la période romaine. La nature des offrandes anciennement recueillies sous le temple de Mercure ne permet pas d'affirmer qu'il était dédié à cette même divinité tutélaire. Le nombre relativement élevé de pièces d'armement plaide, au contraire, pour une divinité guerrière apparentée au Mars Caturix des sanctuaires belges. La rareté des offrandes monétaires mérite par ailleurs d'être relevée, comparativement aux horizons romains ou au sanctuaire de Corent qui a, lui aussi, livré des armes. L'étroite association des amphores et des monnaies qui caractérise ce dernier site renvoie moins au domaine marchand qu'à la sphère politique: le vin des 
libations et des festins, comme le pouvoir monétaire y constituent les deux facettes d'un ascendant politique illustré par le récit de Poseidonios ou le revers des fameux statères d'or de Vercingétorix, dont la monture surmonte une amphore.

L'étude des pratiques religieuses en pays arverne ne saurait, enfin, faire abstraction des nombreux dépôts au caractère votif avéré ou probable, qui caractérisent la plupart des habitats de la période. Fossés, fosses et puits inscrits au cœur des agglomérations d'Aulnat, La Grande Borne, Gandaillat ou élisée Reclus, ont livré un mobilier qui sort clairement de l'ordinaire domestique : pièces d'armement, lingots (currency bars), inhumations de chiens, de squelettes ou de crânes humains... Si le qualificatif de " sépultures "s'applique à plusieurs d'entre elles, voire à certains ossements isolés - dont le dépôt est également attesté sur les nécropoles voisines de Pontcharaud ou Gandaillat -, d'autres évoquent clairement des pratiques sacrificielles; en témoignent les mutilations volontaires observées sur plusieurs corps : trépanations, amputation des pieds ou d'autres membres, restes d'une lame de couteau en fer encore fichée dans une scapula.

Ces dépôts situés à mi-chemin entre les sphères cultuelle et funéraire ont une tradition très ancienne qui remonte au début du second âge du Fer (Gannat), voire à l'âge du Bronze (Le Brézet...). Ils s'assortissent aux $\mathrm{II}^{\mathrm{c}}-\mathrm{I}^{\mathrm{cr}} \mathrm{s}$. avant J.-C. de grandes quantités de vaisselles à boire et d'amphores vinaires qualifiées de "détritiques ", faute d'analyse taphonomique détaillée. Les études en cours montrent qu'elles ont été sélectionnées et déposées selon des critères identiques à ceux observés sur les sanctuaires. Plusieurs vases comportent des graffites, à l'instar des offrandes céramiques du Puy-de-Dôme (anthroponymes ou figuratifs : guerrier à cheval brandissant une tête coupée, fibules emboîtées, animaux affrontés). Le dépôt de deux amphores décolletées disposées au fond d'un puits d'Aulnat (fosse J), surmonté de plusieurs cols associés à un crâne d'enfant, renvoie aux mêmes pratiques qu'à Corent ou au Brézet. Ce type de dépôt, dont le nombre ne cesse de s'accroître au fil des fouilles, confronte l'archéologue des religions à une réalité nouvelle et troublante : celle de rites sacrificiels, libatoires et funéraires intimement intégrés à l'espace domestique, reproduisant à une échelle plus réduite, voire sous une forme purement symbolique, les formes cérémonielles en vigueur sur les sanctuaires.

M. Poux

\section{RHÔNE-ALPES}

Les textes antiques relatifs aux pratiques cultuelles des Gaulois ne sont guère nombreux, et on notera donc avec intérêt les mentions concernant les Allobroges. À propos de la conjuration de Catilina, Sénèque affirma que : "l'ennemi transalpin [les Allobroges] était frustré depuis longtemps des victimes dues aux bûchers gaulois " (De Beneficiis, $\mathrm{V}, 16,1)$. On peut y voir une allusion à la cérémonie publique quinquennale mentionnée par César et Strabon, cet holocauste au cours duquel victimes humaines et animales étaient brûlées dans des statues de paille et d'osier tressées à l'image de certaines divinités. Ce texte indique que cette pratique était abolie en 6.3 avant J.-C., sans doute depuis le senatus consulte de 97 avant J.-C. interdisant les sacrifices humains en Italie. Pourtant, en 69 avant J.-C., Cicéron, défendant le gouverneur de la Transalpine face à des plaignants gaulois, prit habilement à partie l'assistance en demandant: "qui ignore que ceux-ci ont conservé jusqu'à ce jour la coutume monstrueuse et barbare d'immoler des hommes " (Pro M. Fonteio oratio, XIII-XIV, 30-31). À qui pensait-il en évoquant ces pratiques que Rome, elle-même, n'ignorait pas ? ${ }^{5}$. Aux Gaulois dans leur ensemble ou aux seuls provinciaux représentés par l'Allobroge Induitomaros? Cette interprétation impliquerait le maintien tardif dans la Provincia des sacrifices sanglants pratiqués sous l'autorité des druides, parfois à la demande de particuliers et relatés plus tard par César et Diodore (Bibliothèque historique, $\mathrm{V}, 31)^{6}$.

Ces pratiques n'ont, à ce jour, pas ici d'expression archćologique ; toutefois, on ne peut passer sous silence la découverte récente à Genève - en territoire allobroge d'un jeune adulte enseveli à la manière des " accroupis " d'Acy-Romance (Ardennes). Rien ne vient expliquer les causes de la mort prématurée, ni le traitement particulier du cadavre, mais on ne peut s'empêcher de songer aux accusations romaines ${ }^{7}$ (Haldimann, Moinat, 1999). Enfin, signalons une fibule filiforme de Sainte-Blandine portant le visage d'un personnage borgne, au milieu d'un décor évoquant la construction d'un clayonnage en bois. Rien n'interdit d'y voir la figuration de la divinité chthonienne à

5. Le sacrifice humain le plus récent serait le fait de... César. En 46 avant J.-C., il fit exécuter des militaires rebelles. I.c déroulement de l'affaire a laissé penser à $G$. Dumézil qu'il s'agissait d'un acte plus religicux que simplement judiciaire, s'inspirant du sacrifice de l'October Equus.

6. À partir de l'œuvre de Poseidonios, témoin oculairc vers 101-100 avant J.-C.

7. À propos de Genava, hors sujet dans le présent dossier, il faut rappeler la découverte, lors de la fouille du port gaulois, de restes humains portant des traces de découpe (Bonnct et al., 1989; Cueni, Simon, 1999, p. 296). Plus récemment, les fouilles du Parc de la Grange ont révélé l'existence de niveaux anciens. Parmi la vingtaine de parures vestimentaires datćes du IV e au I ${ }^{\mathrm{er}} \mathrm{s}$. avant J.-C. figurent des exemplaires sacrifiés par torsion (Haldimann et al., 2001, p. 7). 
laquelle Sénèque faisait peut-être allusion... (Chapotat, 1970, pl. V, n 3 ; Perrin, à paraître).

La région Rhône-Alpes est archéologiquement peu documentée sur les licux et les pratiques cultuelles à l'époque préromaine ; ce n'est certainement là que le reflet de la faiblesse des recherches sur l'âge du Fer. Pour l'extrême fin de l'âge du Bronze, la fouille récente d'un dépôt de crémation à Saint-Priest (Rhône) apporte quelques informations. Il s'agit d'une sépulture située à l'intérieur d'une vaste maison sur solins de pierres, proche de deux autres bâtiments, d'un probable tumulus et d'une quinzaine de petits foyers de galets. Une datation effectuée sur une poutre calcinée d'un des bâtiments propose : $2545 \pm 60 \mathrm{BP}$, soit 797-438 avant J.-C. (Lyon-9012). Sans équivalent sur le plan régional, cette construction pourrait être liée à un culte des ancêtres (Bellon et al., 2001 ; Dedet, 2001b, p. 240). Dans le site funéraire de Gorge de Loup à Lyon, quelques individus privilégiés furent ensevelis entre le tout début du VIII et le $\mathrm{V}^{\mathrm{c}} \mathrm{s}$. avant J.-C. au sein d'un probable enclos de palissades en bois, alors qu'un bâtiment sur poteaux porteurs a été construit sur deux tombes féminines - l'une relativement riche (or, ambre), l'autre très modeste - (Burnouf et al., 1989). De plus, l'étude des restes osseux erratiques du site a révélé que d'autres tombes avaient été anciennement détruites; parmi ces restes, on note la présence d'un fragment de crâne humain fraîchement cassé, vestige probable de pratiques indéterminables ( $\mathrm{P}$. Méniel, inédit; voir aussi Boulestin, Jouannet, 2002). On doit mentionner, dans un autre registre, le cas du dépôt de La Chuire au camp de Larina (voir infra notice 11, p. 155-156) dont les mobiliers anciens appartiennent à la fin du Bronze final (IIIa et IIIb), mais aussi au tout début de l'âge du Fer. En effet, le site a livré une bouterolle à ailettes de fourreau d'épée hallstattienne, pièce datable dans les premières décennies du VIII' $s$. avant J.-C. D'autres objets se rattachent à la phase D2-D3 du Hallstatt, plus précisément au courant d'importations massaliotes qui touche la région à partir de la seconde moitié du $\mathrm{VI}^{\mathrm{e}} \mathrm{s}$. avant J.-C. Il s'agit ici de fibules intactes, de fragments d'amphores massaliètes, de vases en céramique grise monochrome et de cruches peintes pseudo-ioniennes. Ce type de mobilier est peu fréquent régionalement et l'on peut songer à son sujet à des dépôts intentionnels. Les vestiges de sanctuaires du premier âge du Fer se rencontrent sous la forme de stèles principalement sur le site fortifié de hauteur du Pègue (Drôme), avec pas moins de 24 exemplaires, et isolément, semble-t-il, sur des sites plus septentrionaux tel PierreAiguille à Crozes-Hermitage (Drôme) (Lagrand, 1981 ; Bessac, Bouloumié, 1985, p. 179 ; Arcelin et al., 1992, p. 236). Ces bétyles, plusieurs fois étudiés, appartiennent probablement à un lieu de culte ancien, peut-être des VII ${ }^{c}$ $\mathrm{VI}^{\mathrm{c}}$ s. avant J.-C. ${ }^{8}$.

Aucun espace cultuel n'est attesté pour le début du second âge du Fer. Au camp de Larina, après un hiatus de plus de deux siècles, on note la reprise d'activités, sans doute cultuelles, dont le produit aboutira dans la faille de La Chuire (Perrin, 1990); paradoxalement, le plateau de Larina n'a pas livré de vestiges d'une occupation de La Tène B2-C, alors que se multiplient les témoignages d'une fréquentation durant La Tène D1. C'est également à cette date que se constitue le mobilier rassemblé sur la colline de Sainte-Blandine, dans les alentours de sanctuaires gallo-romains; une révision du matériel a permis de préciser la composition de l'ensemble (voir infra, notice 23, p. 165-168). Sur l'oppidum du Crêt-Châtelard à SaintMarcel-de-Félines (Loire), une trentaine de puits datés de La Tène D2 jusqu'aux premières décennies de notre ère ont été découverts à la fin du $\mathrm{XIX}^{\mathrm{e}} \mathrm{s}$. ; certains ont livré des fruits, glands et pommes, du bois de chêne, du buis, des aiguilles de pin. L'un d'entre eux ( $\left.n^{\circ} \mathrm{IV}\right)$, appartenant à la première occupation du site, a livré une statuette en bois (noyer) figurant un personnage accroupi, accompagnée, semble-t-il, de bois de cerf (Cernunnos?) ainsi que d'un chaudron et d'entraves. Une fonction cultuelle semble devoir être envisagée pour ce puits, mais également pour les $\mathrm{n}^{\text {os }} \mathrm{X}$ et $\mathrm{XX}$ qui ont livré des restes humains (Orengo, à paraître). Dans les habitats groupés ouverts du territoire des Ségusiaves, diverses observations plaident en faveur de pratiques cultuelles. À Rodumna (Roanne), l'étude des restes humains erratiques, fréquents dans les sites de l'âge du Fer (Saint-Paul-Trois-Châteaux et Lyon au $\mathrm{V}^{\mathrm{c}} \mathrm{s}$. avant J.-C.), a montré l'existence de découpes sur un fémur d'adulte (Méniel, 1997, p. 183), tandis qu'à Feurs, une fosse a livré trois vases intacts, dont une forme peinte, accompagnés d'un couteau et de céréales; l'ensemble pourrait constituer un dépôt d'offrandes (Vaginay et al., 1987, p. 40-41). De même, une fosse de l'habitat de Goincet à Poncins (Loire) a fourni un ensemble de céramiques dans lequel on trouve plusieurs récipients à pâte micacée et décors estampés remarquables : une cruche à bec tubulaire, un bassin et une coupe à pied peinte pourraient constituer un service destiné à des usages rituels (Vaginay, Guichard, 1984 ; Vaginay et al., 1987, p. 40-41). Enfin, sur le site de l'antique Lugdunum, le réexamen des données des fossés du Verbe-Incarné permet de conforter les interprétations de type cultuel (voir infra notice 12, p. 156-158). Quelques enceintes quadrangulaires isolées sont connues régionalement, notamment à Amplepuis (Rhône) ou

8. Aimable information de Frédérique Sergent, doctorante à l'université d'Aix-en-Provence. 
Cleppé (Loire) ; toutefois les preuves d'activités cultuelles y sont trop réduites pour permettre de qualifier ces sites de sanctuaires.

L'existence de niveaux gaulois antérieurs aux sanctuaires gallo-romains n'est guère attestée en région RhôneAlpes, les seuls documents préromains se limitant à quelques monnaies gauloises, massaliotes ou même républicaines (Andance et L'Abeille en Ardèche, Annecy en HauteSavoie), voire à quelques objets non identifiés, préromains par leur position stratigraphique (Viuz à Faverges en HauteSavoie) (Serralongue, 2002, p. 160). Une exception notable concerne le sanctuaire helvien des Bagnols à Albala-Romaine (Ardèche) d'où provient un mobilier d'habitat de la fin du ${ }^{\text {er }}$ s. avant J.-C., dans lequel un nombre élevé d'anneaux et de grafittes sur céramique doit être lié à un premier sanctuaire indigène (Dupraz, 2000).

Les découvertes d'objets métalliques en milieux aquatiques sont attestées, essentiellement à Lyon, à Grigny (Rhône) (Durand, 1993), ainsi que naturellement dans la Saône (Gallay, Huber, 1972) ; quantitativement, les découvertes paraissent moins nombreuses qu'en Bourgogne, les mobiliers de La Tène étant peu représentés. On notera la bonne représentation des armes, notamment celles de la fin de l'âge du Bronze ; quelques objets se rapportent à la fin de l'âge du Fer : casques de Lyon, de Belleville (Rhône) et des Avenières (Isère), poignard à marque lunaire (de Lyon ?), épée à sphères de Villefranche-sur-Saône (Rhône), un type rare à la chronologie parfois discutée (Wehrberger, 2000, p. 80), fréquent dans le lit des fleuves et des rivières. Le fait votif n'est guère facile à déterminer et bien des explications peuvent être avancées pour expliquer la présence sur des hauts-fonds d'objets que l'on retrouve rarement en milieu terrestre : sépultures détruites, naufrages, pertes accidentelles, etc. En revanche, les chenets et cadres en fer de Vienne (Isère), de Saint-Romain-en-Gal (Rhône) et de Saint- Bernard (Ain) - des objets peu communs - pourraient être du mobilier d'usage cultuel volontairement déposé dans les eaux du Rhône et de la Saône. Enfin, il faut signaler la découverte en 1880 à Lyon dans la Saône d'une remarquable tête de divinité au torque, proche de celle du dieu de Bouray-sur-Juine (Essonne). Là aussi, on pourrait incliner, sans argument précis, pour un dépôt volontaire.

F. PERRIN 


\section{NOTICES}

\section{NOTICE 1}

\section{ACCOLAY (YONNE)}

\section{PASSerelle RUinéE}

$\mathrm{Au}$ lieu-dit Passerelle ruinée, au pied de l'oppidum de Bétry à Vermenton et sur les berges de l'Yonne, les prospections aériennes ont permis de repérer des traces de murs et des fosses qui pourraient correspondre à un petit ensemble cultuel inédit d'origine laténienne. Les prospections pédestres ont mis en évidence deux concentrations de vestiges espacées de $70 \mathrm{~m}$, sur lesquelles ont été observés des tegulae et des pierres de construction antiques, mais aussi de la céramique grossière, de la céramique fine, des tessons d'amphore Dressel 1A et 1B et un bronze éduen. Le deuxième emplacement, au sud-ouest, révèle un angle de fossé quadrangulaire et des fosses qui laissent envisager des aménagements cultuels identiques à ceux fouillés à Nitry (voir infra notice 16, p. 160-162). La fréquentation de ce possible sanctuaire se situe entre La Tène finale et la fin du III $^{\mathrm{e}}$ s. après J.-C.

Bibliographie : Nouvel, 2000 ; Delor dir., 2002.

P. NOUVEL

\section{NOTICE 2}

\section{ARGENTENAY (YONNE)}

\section{Champ aux Os}

Le site, inédit, reconnu par prospections terrestres et aériennes au lieu-dit Champ aux Os se situe dans la vallée de l'Armançon, sur une petite pente dominant d'importantes sources pérennes. Le matériel recueilli en surface est assez restreint en ce qui concerne l'époque laténienne, mais les indices sont plus nombreux pour les périodes plus tardives. La zone cultuelle semble marquée par la présence d'un fanum gallo-romain qui a fourni en surface, en dehors du matériel antique, de la céramique laténienne, des fragments d'amphore Dressel 1, un potin LT 9155 et un quinaire du type Kaletedou.

P. NOUVEL
NOTICE 3

\section{AUTHUMES (SAÔNE-ET-LOIRE)}

\section{LE TERTRE}

Ce site est localisé dans la vallée du Doubs, en aval de Dole. Il s'agit d'un établissement s'étendant sur 1 ha, clos par un puissant fossé délimitant un espace quadrangulaire (Barral, Bossuet et al., 2001). Cet habitat a connu deux phases d'occupation, à La Tène Dla puis à La Tène D2, séparées semble-t-il par un hiatus. Présentant certaines des caractéristiques des fermes indigènes de La Tène finale, il s'en sépare par le faciès mobilier, riche et diversifié, comparable à celui des habitats groupés de la même région (Verdun-sur-le-Doubs, Grozon). La présence d'objets rares (fibule en argent, applique de char, etc.) indique un établissement situé sur une voie de communication majeure et clairement lié à une population aisée, voire à une élite aristocratique. Une seule structure peut ĉtrc associćc à un fait «cultuel » : une amphore Dressel 1B brisée, associée à une patère en campanienne Boïde, à une coupe et à un gobelet à décor ocellé en céramique indigène pratiquement complet, auxquels étaient mêlés quelques fragments de bûches carbonisées. Cet ensemble peut être attribué au deuxième ou au troisième quart $d u \mathrm{I}^{\mathrm{cr}} \mathrm{s}$. avant J.-C. Là encore, l'interprétation cultuelle repose sur une série d'indices convergents: la cohérence de l'ensemble, son organisation, son caractère limité dans l'espace, le contraste existant avec les ensembles détritiques du site.

Bibliographie : Barral, Bossuet et al., 2001.

P. BARRAI.

\section{NOTICE 4}

\section{BRIENON-SUR-ARMANÇON (YONNE)}

\section{FonTAINE DE THURY}

Aux lieux-dits Champ de la Cure et Fontaine de Thury a été repéré et sondé un important sanctuaire organisé autour des sources pérennes de Thury. Les prospections aériennes (1988-1998) ont révélé le plan des aménagements 


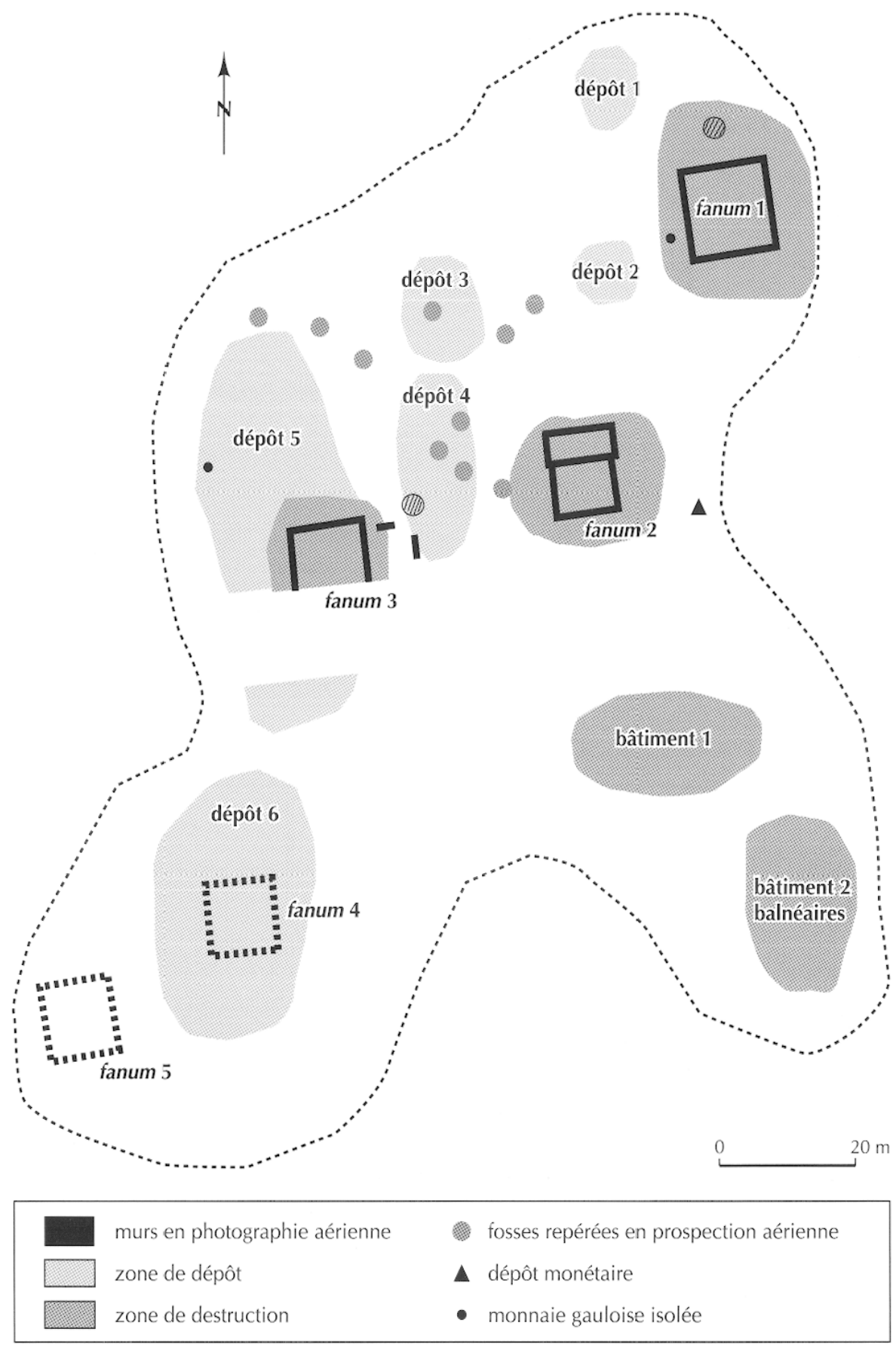

Fig. 76 - Brienon-sur-Armançon (Yonne). Sanctuaire laténien et antique de Champ de l'Areigne d'après les prospections aériennes et terrestres (DAO P. Nouvel).

antiques alors que les prospections terrestres se sont multipliées. Dans le matériel, essentiellement du Bas-Empire, on note la présence de céramiques laténiennes, d'un bronze " sénon " (type LT 7493) et d'un statère globulaire à la croix qui indiquent une fréquentation dès La Tène finale, concentrée à proximité de la source et probablement en grande partie masquée par les occupations postérieures.

\section{Champ de L'Areigne}

Au lieu-dit Champ de l'Areigne, à proximité de l'ensemble cultuel de Thury, a été prospecté un important sanctuaire d'origine laténienne dont la superficie avoisine 1 ha (Labaune et al., 1999; Nouvel, 2000, vol. I, p. 107-121 et pl. 28). D'abord repéré en prospection terrestre, son plan 
inédit nous est précisé par quelques clichés aériens (fig. 76). $\mathrm{Au}$ nord, trois bâtiments rectangulaires ne présentent aucune trace de galerie. Cependant, la présence de fosses et la concentration du matériel aux alentours permettent de les considérer comme des cellae avec galerie périphérique en matériaux périssables ( fana 1,2 et 3 ). Une tache noire où les fibules sont très abondantes se trouve plus au sud (dépôt 2). Les photographies aériennes laissent entrevoir une large fosse (dépôt 4) qui a livré céramiques et monnaies, en particulier laténiennes en abondance, alors que plus au sud se rencontre une concentration de monnaies gauloises (dépôt 5). Au sud-ouest se trouvent encore trois concentrations de matériel à proximité de deux bâtiments du même type que ceux précédemment décrits (fana 4 et 5). Ils ont également été considérés comme des fana, bien qu'aucun cliché aérien ne le confirme. En effet, dans ces structures la concentration en monnaies gauloises est particulièrement forte (dépôt 6). L'abondant mobilier recueilli en prospection permet de se faire une idée correcte de la période de fréquentation (Labaune et al., 1999 ; Nouvel, 2000, vol. I, p. 116-117). Parmi 61 monnaies pré-impériales, 40 sont gauloises (un quart de statère rème, des quinaires des Éduens, Lingons, Séquanes et Volques Tectosages, 1 potin melde, 17 potins sénons, 1 potin éduen, 13 bronzes sénons et 1 indéterminé) ; par ailleurs, deux rouelles pendentifs, une pendeloque en or, ainsi qu'une oreille animale en bronze forment l'csscnticl du matériel laténien.

On remarque une certaine sélection du matériel dans les dépôts ainsi qu'une fréquentation principale des fana 4 et 5 au cours de La Tène finale et au début de notre ère. Il s'agit d'un probable sanctuaire rural à proximité de l'agglomération laténienne et antique d'Avrolles/Eburobriga.

Bibliographie : Labaune et al., 1999 ; Nouvel, 2000 ; Delor dir., 2002.

P. NOUVEL

\section{NOTICE 5}

\section{CHAMPDIVERS (JURA)}

\section{ILION ChaUdaT}

Le gisement, dont l'extension n'est pas connue, se situe en bordure du lit actuel du Doubs, sur sa rive gauche. Il s'agit d'une zone anciennement marécageuse, comportant plusieurs méandres fossiles. Les objets connus, recueillis sur une vingtaine d'années, ont été découverts lors d'exploitations de gravières sans contexte topographique et stratigraphique précis (Canet, 2000 ; Rothé, 2001). Au total une soixantaine d'objets ont été récupérés (outils, armes, instruments de batellerie et de pêche, éléments de harnachement et de char), la majeure partie étant attribuable au second âge du Fer ; on note la présence d'armement : deux pointes de lance et quinze épées, certaines dans leur fourreau, d'autres à l'état de fragments séparés, deux présentant des traces de bris intentionnel. La datation de ces différentes armes s'étend de La Tène B2 jusqu'à La Tène D2. De plus, une côte de maille - un équipement défensif peu fréquent datable de La Tène $\mathrm{C}$ ou $\mathrm{D}$ - aurait été découverte (non vidi). L'instrumentum domestique et agricole est représenté par 6 haches, 2 coutelas, 1 couteau, 2 faucilles, 1 faux auxquels s'ajoutent 1 chaîne et 1 crochet de crémaillère de suspension de chaudron. Des barres (1 de type pyramidal, 4 du type currency bar) se rapportent aux activités métallurgiques. Enfin, on note la présence d'une entrave de prisonnier, objet rare déjà rencontré en milieu fluviatile, notamment dans la Saône (un recensement sommaire permet d'évaluer à dix le nombre de ces objets trouvés dans les moyennes vallées de la Saône et du Doubs).

Bibliographie : Canet, 2000 ; Rothé, 2001.

P. BARRAL

\section{NOTICE 6}

\section{CHAMPLOST (YONNE)}

\section{Foulon D'AVRolles}

L'antique Eburobriga s'étend pour partie sur la commune de Champlost, au nord du Créanton. C'est ici que se sont tout d'abord implantées les nécropoles du Hallstatt final en rapport avec une occupation de hauteur, puis, à partir du II ${ }^{c}$ s. avant J.-C., une agglomération et un sanctuaire de plaine. Au bord du Créanton, les prospections aériennes ont montré qu'au moins trois fana sans galerie avaient été reconstruits en dur à l'époque antique, de même qu'un bâtiment sur façade tourné vers la rivière. Les prospections terrestres ont fourni un riche mobilier composé de céramiques laténiennes (céramiques non tournées et tournées, importations, amphores Dressel $1 \mathrm{~A}$ et B), de matériels métalliques (fibules, pendentif pédiforme...) et surtout de nombreuses monnaies : outre une quarantaine de monnaies romaines, on dénombre 3 quarts de statère en or fin (1 LT 8697, 2 inédits), 9 bronzes frappés inédits « au cerf ", de nombreux potins LT 9155 , LT 7417 et LT 7388, 1 potin imitation de Marseille, 2 potins inédits, 3 potins à la " tête diabolique ", 1 bronze indéterminé, 2 bronzes sénons, 1 bronze carnute (Nouvel, 2000; Barral, Guillaumet, Nouvel, 2002). 
Ce sanctuaire a été fréquenté durant La Tène C2-D2 comme le montrent la céramique et les amphores abondantes. L'absence de fouille et d'étude du matériel limite ici aussi la portée des informations recueillies, mais son implantation en bordure de l'important centre d'Avrolles/ Eburobriga et la richesse des découvertes monétaires et céramiques qui y ont été effectuées laissent cependant supposer l'importance de ce lieu de culte.

Bibliographie : Nouvel, 2000 ; Barral, Guillaumet, Nouvel, 2002.

\section{P. NOUVEL}

\section{NOTICE 7}

\section{CLERMONT-FERRAND (PUY-DE-DÔME)}

\section{LE BRÉZET}

C'est un groupe de vestiges situés à la confluence des cours d'eau de l'Artière et la Tiretaine, en limite sud-est de Clermont-Ferrand. Le site est contigu aux habitats d'Aulnat (La Grande Borne, Élisée-Reclus, Gandaillat) et à la nécropole gauloise de Pontcharaud identifiés à la capitale du peuple arverne aux III $^{\mathrm{e}}$ et II ${ }^{\mathrm{e}} \mathrm{s}$. avant J.-C. Implanté dans une cuvette marécageuse périodiquement inondée, Le Brézet s'en distingue par l'absence de toute trace d'aménagements durables, plans d'habitat, sols ou voies de circulation. La seule structure se résume à un fanum galloromain à cella carrée dont la fondation remonterait à la période augustéenne.

Le site comporte une longue séquence d'occupation, signalée dès le XIX $\mathrm{XI}^{\mathrm{e}} \mathrm{s}$ : mégalithes, sépultures et très nombreuses céramiques, datés du Néolithique à la fin de l'âge du Fer. Ces dernières incluent une part remarquable d'amphores républicaines (types gréco-italiques et Dressel 1A), accumulées sur le gisement à hauteur de plusieurs dizaines de milliers de tessons. Une intervention effectuée en 1962, rue Jules-Verne, a livré au moins 80 Dressel 1A, pour la plupart complètes ou amputées de leur col, alignées côte à côte et tête-bêche au fond d'un fossé tapissé de bois. Des sondages de diagnostic y ont mis en évidence d'autres dépôts à caractère cultuel et/ou funéraire : amas céramiques organisés, alignés ou disposés en cercle, sépultures, restes humains et animaux enfouis dans des fosses ou des puits. L'hypothèse de dépotoirs d'habitat est aujourd'hui écartée pour celle de dépôts volontaires constitués selon des normes de sélection et d'agencement précises. L'un de ces puits a livré une sélection de vases à boire et d'amphores vinaircs soumiscs à un dćcolletage et à un bris volontaire interprétée à la lumière de rites libatoires. Une fouille extensive a permis de conforter leur vocation cultuelle, tout en précisant leur fonction et leur chronologie. Le décapage exhaustif de trois parcelles au sud du site a mis en évidence un réseau de structures fonctionnant de manière concomitante : bâtiment, cavités rituelles (puits et fosses), fossés, dépôts de surface et épandages de mobiliers.

Un grand fossé d'enceinte $(9 \mathrm{~m}$ de large pour $1 \mathrm{~m}$ de profondeur) semble délimiter les vestiges au nord-ouest. De son comblement ont été extraites une dépouille de suidé en connexion ainsi que de très grandes quantités de céramiques, parmi lesquelles de nombreuses formes complètes. La seule structure conservée en élévation est un petit bâtiment rectangulaire de $6 \mathrm{~m}$ sur $4 \mathrm{~m}$, en matériaux légers, sur un socle de gros blocs de basalte encadrés par plusieurs poteaux porteurs supportant peut-être une couverture de grandes tuiles en terre cuite. Une entrée était aménagée au centre de la façade nord, précédée d'une sorte de porche sur deux poteaux. À l'intérieur, une grande fosse quadrangulaire placée devant l'entrée (autel creux ?), comblée de pierres mêlées à quelques fragments d'os, dont un fragment humain. Un tronçon d'orgue basaltique, découpé et strié de coups de lame, était disposé contre la paroi faisant face à l'entrée (pierre d'autel ?). La forme du bâtiment, son module et sa technique de construction présentent de très fortes analogies avec l'enclos cultuel découvert en 2001 au centre du sanctuaire de Corent, dont il constitue en quelque sorte la version réduite. La parenté des aménagements exclut a posteriori l'hypothèse d'une structure domestique, déjà peu plausible à défaut de niveaux d'habitat, au profit d'une fonction religieuse ou collective dans un sens large, en relation avec les dépôts environnants.

Plusieurs structures en creux ont été fouillées au sud-est du bâtiment. Deux puits en particulier se distinguent par la présence de dépôts volontaires et organisés. Dans le premier, profond de $1,50 \mathrm{~m}$, gisait une dépouille de cheval en connexion; entre les membres antérieurs et postérieurs était déposé un petit coffret rectangulaire contenant les éléments en fer du harnachement, surmonté d'un torque en alliage cuivreux. Plusieurs céramiques et une perle en verre complétaient le dépôt. Le second puits, situé à quelques mètres et profond d'environ $2 \mathrm{~m}$, comportait à sa base un rétrécissement cuvelé de planches en bois, entouré d'une sorte de banquette supportant trois panses d'amphores complètes, décolletées, l'une découpée dans le sens de la longueur, associées à une meule en basalte brisée. La forme du puits et la sélection des dépôts établissent un lien direct avec la série des puits "à offrandes " de Gaule aquitaine, en particulier avec ceux du sanctuaire de la Cascrnc Rauch à Rodez. $\Lambda$ mphores vinaires et meules à grains y sont la composante privilégiée de rites de libations 


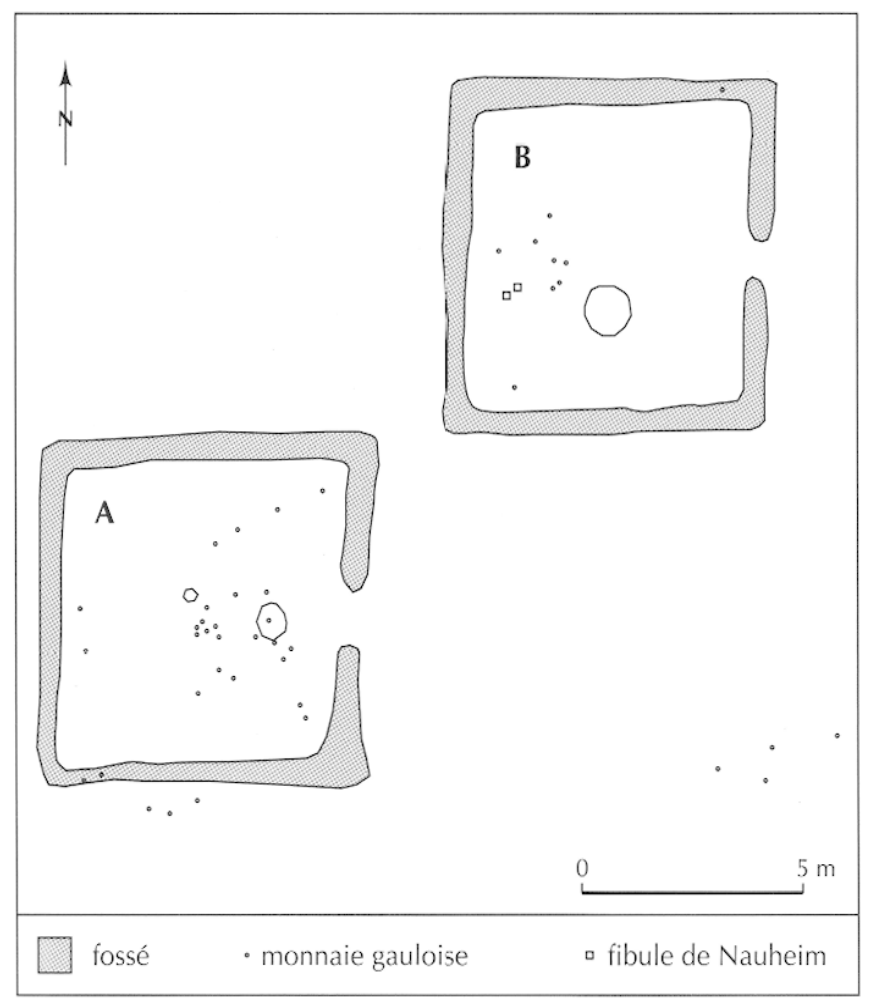

Fig. 77 - Fontaine-la-Gaillarde (Yonne). Plan des structures fouillées de La Grande Chaume (d'après J.-P. Sarrazin, in Delor, Rolley, 1989).

dédiés à des divinités chthoniennes ou agraires, utilisant un dispositif commun à ce type de sanctuaires: trois puits marquaient la terminaison d'un long fossé permettant peutêtre l'écoulement des boissons dans leur comblement. L'offrande de vin ou d'amphores s'illustre, au Brézet, par d'autres dépôts: amphores reconstituées à l'aide de fragments appartenant à plusieurs récipients, tessons souvent disposés en cercle autour d'un gros jeton retaillé dans une panse ou autour d'un col complet fiché verticalement recelant un dépôt de dé à jouer en os. Ce dernier dépôt en évoque un autre, formé de deux osselets disposés côte à côte contre un fragment d'anse d'amphore. Dé à jouer et astragales documentent, comme sur les sanctuaires grecs, l'existence de rites de divination au cours desquels le vin et l'ivresse jouaient visiblement un rôle important.

L'ensemble du mobilier présente un faciès très cohérent de La Tène C2-D1 (milieu et fin du II ${ }^{\mathrm{c}} \mathrm{s}$. avant J.-C.) : majorité d'amphores gréco-italiques tardives, de Dressel 1 et de formes céramiques anciennes (campaniennes A, jattes d'Aulnat). Le site ne semble plus occupé par la suite, à l'exception du fanum et de quelques sépultures du début de l'époque romaine. La situation et l'ampleur des vestiges sur plusieurs hectares suggèrent un lien avec la mention par Strabon du premier sanctuaire du territoire arverne, localisé à proximité de leur capitale, Aulnat, délaissée pour l'oppidum du puy de Corent avant de se réincarner à Clermont-Ferrand sous le nom d'Augustonemetum? Il est peu probable, en revanche, que l'ensemble de la zone ait été occupé de manière continue. Le caractère instable du substrat, responsable de l'enfoncement des dépôts, plaide plutôt pour un lieu réservé aux activités religieuses et funéraires, fréquenté périodiquement par la collectivité pour des occasions particulières agrémentées de festins, de sacrifices et de libations.

La présence, au cœur même des vestiges laténiens, de nombreux dépôts à caractère funéraire et/ou cultuel datés du Néolithique ancien à l'âge du Bronze final (sépultures, inhumations en fosse de squelettes décapités ou de carcasses animales entières, dépôts de crânes, amas de céramiques brûlées et chenets céramiques décorés) invite en revanche à penser qu'ils s'inscrivent dans le prolongement d'une tradition antérieure.

Bibliographie : Provost, Mennessier-Jouannet, 1994; Deberge et al., 2000 ; Poux, Vernet, 2001.

M. Poux

\section{NOTICE 8}

\section{FONTAINE-LA-GAILLARDE (YONNE)}

\section{La Grande Chaume}

Ce petit site, localisé sur les plateaux du Sénonais, au nord-est du confluent de la Vanne et de l'Yonne où s'est développée l'agglomération de Sens, est implanté sur le versant d'une petite vallée sèche et a fait l'objet d'une fouille extensive (Delor, Rolley, 1989, p. 178). Son originalité réside dans sa proximité avec une importante nécropole dont les vestiges les plus anciens remontent à La Tène A. À $150 \mathrm{~m}$ à l'ouest de cette dernière, deux enclos quadrangulaires de $7 \mathrm{~m}$ de côté, ouverts à l'est, sont marqués par des fossés profonds de 0,15 à $0,25 \mathrm{~m}$ seulement (fig. 77). Bien que similaires morphologiquement aux enclos sépulcraux situés à proximité, ils n'ont pas fourni d'indices funéraires laténiens. Fossés et couche d'occupation remaniée n'ont livré que quelques vestiges céramiques inédits et une importante série monétaire (68 individus). De l'enclos A provient une série de trente monnaies assez homogène, majoritairement des bronzes frappés attribués aux Sénons (principalement type La Tour 7493) et quelques frappes de l'orbite carnute et suessionne. Le second enclos (B) a livré, regroupé sur une faible superficie, six bronzes "sénons ", un quart de statère LT 8030 et trois fibules de Nauheim. Les frappes monétaires, épigraphes ou non, sont 
à replacer dans le deuxième ou le dernier quart du $\mathrm{I}^{\mathrm{er}} \mathrm{s}$. avant J.-C.

Bibliographie : Delor, Rolley, 1989.

P. Nouvel

\section{NOTICE 9}

\section{FONTENOY (YONNE)}

\section{VALLÉE DE SOLMET}

Le sanctuaire laténien et gallo-romain de Fontenoy a fait l'objet de fouilles très mal documentées au milieu du XIX ${ }^{\mathrm{c}} \mathrm{s}$. (Duché, 1852). Il se situe dans une large vallée sèche qui révèle en hiver des points d'eaux nombreux et où les circulations karstiques semblent importantes. Ce sont les recherches aériennes qui ont permis de reconnaître son organisation, marquée par au moins six fana et une zone thermale incluse dans un péribole (Delor, Rolley, 1989, p. 175). Quelques prospections de vérification au sol, effectuées au cours des années 1990, ont permis de recueillir, au milieu d'un matériel gallo-romain, quelques éléments céramiques laténiens (amphore Dressel, céramique) et deux potins dont un du type LT 7417.

Bibliographie : Duché, 1852 ; Delor, Rolley, 1989.

P. NOUVEL

\section{NOTICE 10}

\section{GLUX-EN-GLENNE (NIÈVRE ET SAÔNE-ET-LOIRE)}

\section{MONT BEUVRaY - BIBRACTE}

Dans le cadre des recherches sur l'oppidum de Bibracte, les aménagements liés à une des principales sources de la montagne ont été explorés entre 1988 et 1996. La structure principale, construite vers le milieu du $\mathrm{I}^{\mathrm{er}} \mathrm{s}$. avant J.-C., est un grand bassin rectangulaire maçonné, de $20 \mathrm{~m}$ par 10 m (Gruel, Vitali, 1998, p. 33). Les couches de décantation et le fond aménagé ont livré un ensemble important de petits objets. À côté de deux séries dominantes, constituées par 148 monnaies et une cinquantaine de pieds et fragments divers de cruches et récipients en tôle de bronze, dont une passoire à vin (Barral, Richard, 1993), figurent des objets isolés, parmi lesquels un bracelet filiforme en bronze, un anneau en or, une pièce en bois représentant, semblet-il, une paire de testicules traitée en ronde-bosse et un $e x$ voto d'oreille en tôle de bronze (Goudineau, Peyre, 1993, p. 89). Cet ensemble s'est constitué vers La Tène D2 et au début de l'époque augustéenne. Si la présence de nombreux débris de récipients en tôle de bronze peut être considérée comme relativement normale dans un contexte de fontaine, en revanche, les monnaies et l'oreille en tôle de bronze sont indubitablement liées à des gestes votifs. Ce grand bassin, dont la fonction n'était pas nécessairement univoque, a donc été le lieu de pratiques rituelles. On signalera également une petite fosse dans la partie orientale de la Pâture du Couvent qui a livré une douzaine de vases, entassés et brisés, presque complets. Il s'agit de céramiques lissées fumigées ou à décor géométrique peint (Cain, Rieckhoff dir., 2002, p. 141-142), avec une nette prédominance de récipients à liquides (pots, bouteilles, tonnelets, cruche). Cet ensemble est datable de La Tène D1b.

Bibliographie : Barral, Richard, 1993 ; Goudineau, Peyre, 1993 ; Gruel, Vitali, 1998 ; Cain, Rieckhoff dir., 2002.

P. BARRAI

\section{NOTICE 11}

\section{HIÈRES-SUR-AMBY (ISÈRE)}

\section{Camp de LaRina et faulle de La Chuire}

Dominant les plaines du Rhône et de l'Ain, le camp de Larina est un site fortifié sur un à-pic de près de 27 ha, délimité par un rempart non daté de près de $1 \mathrm{~km}$ de long. $\mathrm{Au}$ pied du site se développe une nécropole tumulaire de l'extrême fin du Bronze final d'au moins une dizaine de tertres, parmi lesquels le tumulus Géraud, riche inhumation (orfèvrerie, armes, vaisselle de bronze) datant des années 800 avant J.-C. Cependant, l'un de ces tertres livra en 1818 un remarquable dépôt de crémation à mobilier privilégié du début du I ${ }^{\text {er }}$ s. avant J.-C. (Perrin, Schönfelder, à paraître). Le site fortifié témoigne d'une fréquentation dès les débuts du Bronze final, mais surtout au cours des phases IIIa et IIIb $\left(\mathrm{X}^{\mathrm{e}}-\mathrm{IX}^{\mathrm{e}}\right.$ s. avant J.-C.). Cependant, l'existence de fours "polynésiens " et de fosses-dépotoirs sans unités de stockage ni vestiges d'habitat pourrait laisser penser à un espace à vocation spécialisée, peut-être un lieu de rassemblements festifs en marge d'un habitat détruit par les carrières, voire d'habitats dispersés aux alentours du site. Outre de rares structures du premier âge du Fer le camp fut ensuite occupé durant La Tène D1 comme le montrent prospections et fouilles de structures antérieures à un habitat mérovingien : près d'un millier de fragments d'amphores républicaines, de la vaisselle campanienne, plusieurs dizaines de monnaies allobroges et massaliotes, ainsi qu'une trentaine de bracelets en verre. Un bâtiment ( $n^{\circ}$ XIII) construit sur un soubas- 


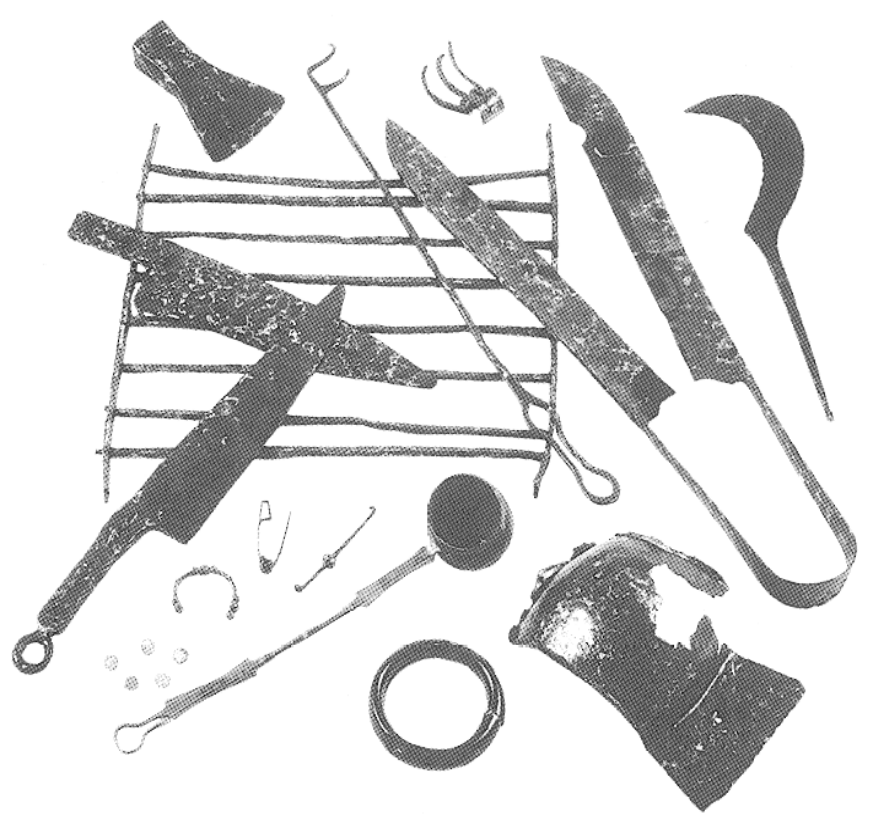

Fig. 78 - Hières-sur-Amby (Isère). Mobilier de La Tène (photo C. Thioc, pôle archéologique du Rhône).

sement en pierres sèches a livré l'essentiel des mobiliers laténiens en place ; il semble assez différent des autres pour pouvoir être attribué à l'âge du Fer mais reste sans fonction précise.

La falaise bordant le site est entaillée de multiples failles dont celle de La Chuire à l'aplomb de la tourbière de Verna. Explorée dès le $\mathrm{XIX}^{\mathrm{e}}$ s., cette faille sera sondée à plusieurs reprises à partir des années 1950 . Le mobilier exhumé sur environ $60 \mathrm{~m}^{2}$, sans contexte stratigraphique homogène semble-t-il, comprend plus de 400 objets ou fragments métalliques essentiellement en fer (fig. 78), près de 30000 tessons de céramique et des centaines de restes osseux (animaux essentiellement); vu la faible superficie, ce matériel doit représenter une partie minime de ce qui figure dans la faille.

L'âge du Bronze final est bien attesté, essentiellement par de la vaisselle parfois à décors peints. On note la présence de quelques vestiges du Hallstatt Cl et d'autres de typologie méridionale de la fin du $\mathrm{VI}^{\mathrm{e}} \mathrm{s}$. avant J.-C. Comme sur le plateau on observe un hiatus pour les $\mathrm{V}^{\mathrm{e}}$ et $\mathrm{IV}^{\mathrm{e}} \mathrm{s}$. avant J.-C. Les premiers objets laténiens appartiennent à La Tène B2 et surtout C1, époques totalement absentes sur le plateau. En revanche, comme sur ce dernier, la faille a livré un abondant matériel céramique et métallique de La Tène D1.

Si l'on exclut l'idée d'un colluvionnement, plusieurs obscrvations ćcartent unc interprétation comme dépotoir. En effet, le mobilier métallique est surtout constitué d'objets intacts, souvent peu usés, parfaitement réutilisables, comparables à ceux du dépôt de Sainte-Blandine à Vienne (voir infra notice 23, p. 165-168). De plus, quelques pièces (fourchette, faux, fibules, gouge, gril, fourreau probablement...) présentent des destructions assurément volontaires, analogues aux manipulations reconnues sur des objets funéraires et cultuels. Dès lors, l'hypothèse d'un mobilier de nature votive volontairement déposé dans la faille semble pertinente. Se pose alors la question de savoir s'il s'agit d'artéfacts provenant d'un sanctuaire non localisé situé sur le plateau ou d'un dépôt dans un site naturel remarquable, dépourvu - du moins en apparence - d'aménagements construits. La faille de La Chuire aboutit directement à la tourbière de Hières-sur-Amby, distante toutefois de plusieurs centaines de mètres ; il est donc difficile de ce point de vue de rapprocher La Chuire des dépôts en eaux stagnantes tels celui de La Tène. De plus, à la différence de bien des ensembles présumés votifs, le mobilier témoigne d'une évidente sous-représentation de l'armement; bien que le gisement ne soit que partiellement connu, la comparaison avec le site de Sainte-Blandine semble valider cette observation. La Chuire constitue donc un ensemble caractéristique des pratiques cultuelles des Allobroges préromains. L'époque impériale verra l'implantation d'un temple dédié à Mercure ainsi que d'un fanum des $I V^{\mathrm{e}}-V^{\mathrm{e}} \mathrm{s}$. après J.-C.

Bibliographie : Verger, Guillaumet, 1988 ; Perrin, 1990 et 2002, p. 32-33 ; Perrin, Durand, 2002 ; Perrin, Schönfelder, à paraître.

F. Perrin et P. Porte

\section{NOTICE 12}

\section{LYON (RHÔNE)}

\section{LE VERBE-INCARNÉ}

Les "fossés à amphores " du plateau de la Sarra ont été découverts lors d'une fouille de sauvetage programmée, de 1979 à 1987 dans une propriété de la congrégation religieuse du Verbe-Incarné. Leur réexamen a permis de compléter les premières études et de proposer de nouvelles hypothèses pour l'interprétation et la datation des structures.

Les vestiges de La Tène finale consistent en un réseau de fossés creusés dans le lœss, implanté sur le point culminant de la colline de Fourvière, le plateau de la Sarra. Les deux principaux fossés, désignés Amont et Aval, possèdent des dimcnsions relativement modestes $(2,30 \mathrm{~m}$ de largcur, $1,50 \mathrm{~m}$ de profondeur) avec un profil en $\mathrm{V}$ pour le premier 


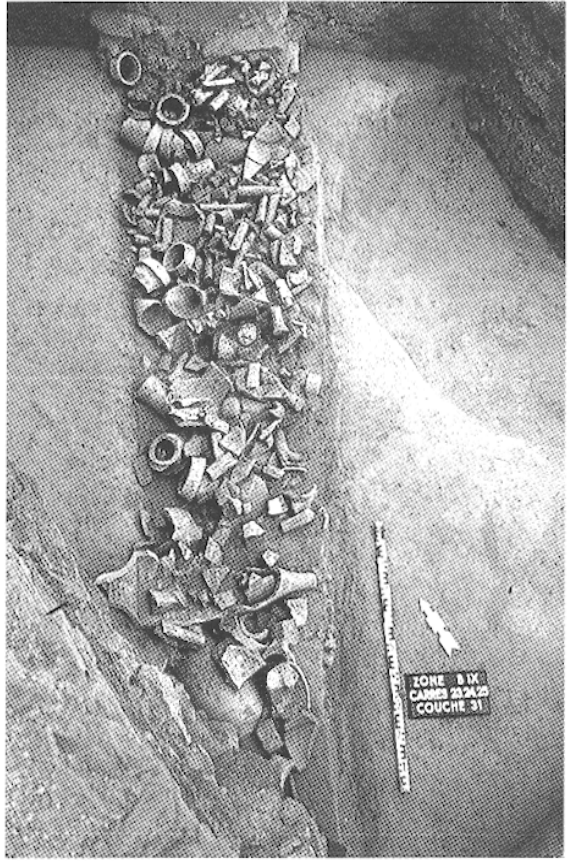

a

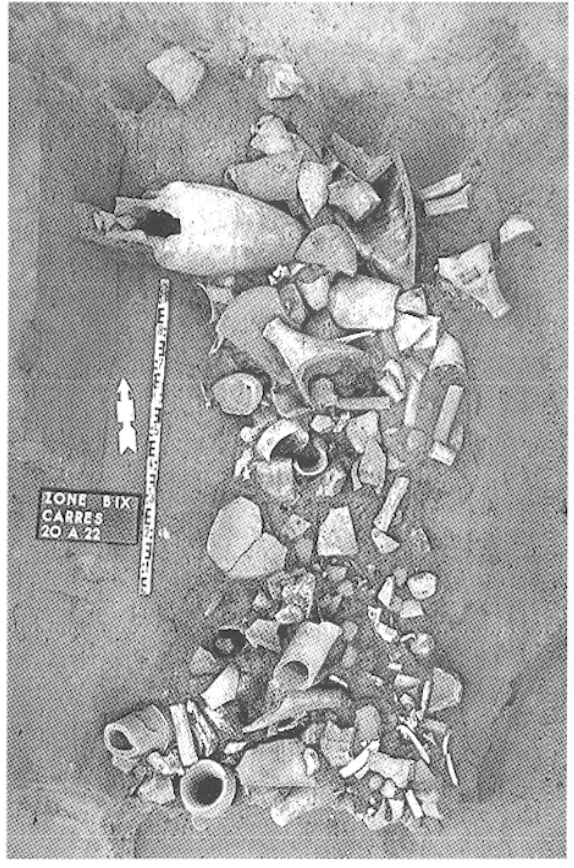

b

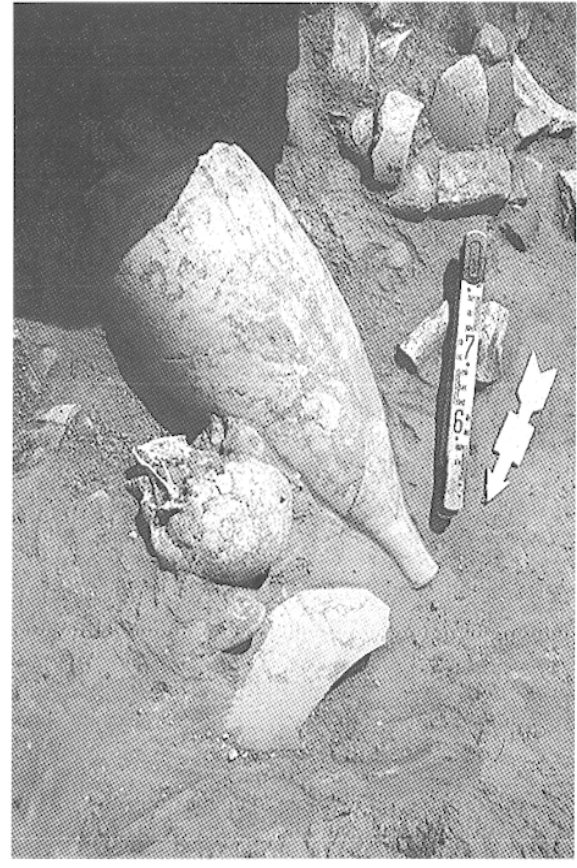

Fig. 79 - Lyon (Rhône). Divers aspects des rejels du fossé Aval du Verbe-Incarné (photos Service archéologique municipal de Lyon).

et en U pour le second, terminé par une rigole présente de manière intermittente sur l'ensemble du tracé, avec de nombreux négatifs de piquets tous les 10 à $35 \mathrm{~cm}$. Rectilignes et orientés nord-est - sud-ouest, les fossés sont quasiment parallèles (distants de $26 \mathrm{~m}$ ), sans que des relations entre les deux aient été établies avec certitude. La présence d'un retour d'angle perpendiculaire au tronçon principal dans la partie méridionale du fossé Aval tendrait à corroborer l'existence d'une double enceinte quadrangulaire de plusieurs dizaines de mètres de côté (reconnue sur plus de $70 \mathrm{~m}$ pour le fossé Aval), délimitant une surface enclose de plus de 1 ha. Dans cette hypothèse, l'interruption de tracé sur plus de $4 \mathrm{~m}$ à l'extrémité sud du fossé Amont pourrait correspondre à un accès; la présence d'une épaisse couche de phosphates minéraux sur le bord amont du fossé témoigne d'une fréquentation régulière des lieux. Enfin, malgré de larges décapages sur le pourtour des structures, l'intérieur de l'enclos apparaît vierge de toute occupation, à l'exception d'une trentaine de trous de piquets, sans organisation apparente, à l'extérieur du fossé Aval.

Les données plaident en faveur d'un comblement général de l'ouvrage rapidement après son aménagement (rareté des traces d'érosion et absence de sédimentation), vraisemblablement avec ses propres déblais accompagnés d'un abondant matćricl archćologique. La disposition des couches, marquée par un fort pendage vers l'ouest, suggère que le colmatage des fossés s'est effectué depuis l'intérieur de l'enclos.

Le comblement du fossé Aval a livré un matériel particulièrement riche, à la différence du fossé Amont qui ne compte qu'une centaine d'artefacts. La composition du remplissage est pour le moins inhabituelle avec plus de $95 \%$ d'amphores à vin de l'Italie républicaine et d'ossements animaux mêlés à des vidanges de foyers (fig. 79). Les céramiques, indigènes et fines méditerranéennes, sont très peu représentées mais, comme la faune, se présentent dans un état de conservation exceptionnel.

Les études de la distribution spatiale des vestiges et des différents dépôts ont démontré l'existence d'importantes accumulations de mobilier, où les différentes catégories de déchets se trouvent étroitement mêlées, concentrées principalement dans la moitié sud du fossé. Les concentrations d'anses et de cols ainsi que la présence de lentilles de cendres et de charbons de bois suggèrent une collecte minutieuse et un transport au moyen de contenants divers.

Avec 14261 fragments, les amphores comptent désormais plus de 700 individus ; estimation largement sousestimée si l'on considère que les tronçons contigus à la plus forte concentration de mobilier n'ont pu être fouillés. Les études ont permis de distinguer deux dépôts correspondant à deux fréquentations distinctes. Le plus ancien, dans l'angle formé par la jonction des fossés, comprend un lot uniquement composé d'amphores gréco-italiques récentes, 
datées du milieu du $\mathrm{II}^{\mathrm{c}} \mathrm{s}$. avant J.-C. Le plus récent est également le plus abondant, avec une majorité d'amphores Dressel IA originaires d'Étrurie, associées à quelques Dressel $1 C^{-}$de la région de Pompéi, datées de la fin $\mathrm{II}^{\mathrm{e}}$-début $\mathrm{I}^{\mathrm{er}} \mathbf{s}$. avant J.-C. par référence au matériel lyonnais et aux épaves méditerranéennes. L'homogénéité typologique des lots, soulignée par la présence de séries d'estampilles et d'inscriptions peintes identiques, se trouve confirmée par la détermination de moins d'une dizaine d'origines différentes, évoquant l'arrivée sur le site de cargaisons complètes d'amphores. La découverte d'opercules encore en place dans les cols estampillés Sestius tend à montrer qu'une partie au moins d'entre elles ont été "sabrées " à proximité immédiate du fossé, avant d'être vidées de leur contenu et rejetées. L'étude taphonomique du mobilier a révélé des traces d'impact très nettes à la base des cols (fractures « hélicoïdales " caractéristiques d'une opération de décolletage toutefois anecdotiques). De même, les panses (une quinzaine reconstituées) portent les traces de chocs violents, opérés vraisemblablement à l'aide des centaines de galets du comblement du fossé. Enfin, la nette disproportion entre les parties hautes de l'amphore et les parties basses, notamment pour le lot le plus ancien, suppose un tri sélectif des différentes constituantes de l'amphore, préalable à l'enfouissement des vestiges.

L'étude de la faune montre que le porc, réservé uniquement à la bouchcric, rcprćsente $95 \%$ du nombre de restes identifiés avec 9331 restes osseux pour un minimum de 57 individus, essentiellement des jeunes mâles abattus à l'âge idéal de consommation (1-2 ans). Leur présence au sein du comblement laisse entendre qu'ils ont été abattus sur place, massivement, puis débités en quartiers vraisemblablement par un seul et même officiant. Le caractère singulier de ce type de consommation se trouve conforté, d'une part, par la rareté des autres espèces appartenant à la triade domestique (4 individus) et, d'autre part, par la présence anecdotique des espèces chassées. Enfin, on note la présence de dépôts plus exceptionnels, constitués de carcasses de chevaux, dont un arrière-train en connexion anatomique, sans traces de découpe mais un démembrement partiel dû à un état de putréfaction avancé, et un crâne isolé, associés de manière étroite à des panses d'amphores décolletées. Autrement plus spectaculaire reste la découverte au milieu de l'amoncellement d'amphores d'un crâne humain (fig. 79c) appartenant à un très jeune adulte gracile (féminin ?). Un examen anthropologique récent ( $F$. Blaizot) n'a pas confirmé une éventuelle décapitation, mais ce type de découpe ne laisse pas nécessairement de traces ; il pourrait s'agir d'un prélèvement à partir d'une sépulture récente découverte lors du creusement du fossé.
Le mobilier métallique est peu abondant avec sept fibules en fer ou en bronze (schéma La Tène II, Nauheim, et filiforme de La Tène III), un anneau en argent, et une possible tarière à bois. Les pièces d'armement se limitent à deux fragments d'umbos de boucliers et, de manière plus inhabituelle, deux balles de fronde en terre cuite. À signaler, la présence tout aussi exceptionnelle d'un aiguisoir ayant pu servir à l'affûtage des couteaux et couperets attestés pour la découpe bouchère. Enfin, les monnaies sont tout aussi rares, avec quatre potins, séquanes et leuques (BN 5368 et 9076), et deux bronzes, dont un arverne (BN 3900).

L'interprétation cultuelle des vestiges, rapidement évoquée en 1989 avant d'être rejetée au profit d'une occupation militaire antérieure à la fondation de la colonie, camp militaire romain ou camp d'auxiliaires gaulois, a depuis été réhabilitée par J. Metzler. Les spectaculaires amoncellements de déchets liés à l'alimentation qui comblaient le fossé Aval, par les quantités de vin et de viande qu'ils mettent en jeu ( 15000 litres, et plusieurs centaines de portions de porc !), consommées dans un laps de temps qui paraît très court, quelques jours ou semaines, dénotent des pratiques de consommation exceptionnelles faisant appel à de nombreux convives. Par ailleurs, la grande rapidité dans l'enchaînement des opérations de collecte, de rejet et d'enfouissement des vestiges, l'organisation très particulière des dépôts, le traitement singulier réservé au matériel amphorique, ainsi que l'exposition et la mise en scène de carcasses d'animaux et de restes humains, trouvent de fructueuses comparaisons dans les pratiques rituelles de sacrifice et de tri sélectif des sanctuaires belges.

Les nombreuses analogies constatées avec les « fossés à amphores de type lyonnais " mis au jour à Aix-en-Provence (Terrain Coq) et Rodez (Caserne Rauch), où le vin et la consommation d'importantes quantités de victuailles jouent un rôle majeur dans le rituel lié au fonctionnement des structures, conduisent actuellement à envisager l'existence d'enclos et de dépôts à caractère cultuel, funéraire ou politique, qui ne sont pas sans rappeler les descriptions faites par Poseidonios des fastueux «banquets " ou "festins » arvernes. Signalons enfin que ce type de vestiges semble loin d'être isolé à Lyon. D'autres structures identiques ont été découvertes sur la colline de Fourvière (rue Le Châtelier, hôpital Sainte-Croix, lycée Saint-Just) ou sur la plaine de Vaise (Souvenir, Marietton, Blanchisseries), pour lesquelles une interprétation d'ordre cultuel tend également à prévaloir.

Bibliographie : Mandy et al., 1987-1988, 1989, 1990 ; Genin, Picon, 1989 ; Metzler et al., 1991 ; Desbat et al., 1997 ; Maza, 1998,2001 .

G. MAZA 
NOTICE 13

\section{MANDEURE (DOUBS)}

\section{Le Clos du Châtrau}

Le sanctuaire est situé au sud-ouest de l'agglomération antique, sur la rive droite du Doubs. L'habitat laténien correspondant n'a pas été découvert. Son existence n'est cependant pas douteuse, en raison de trouvailles ponctuelles, clairsemées mais significatives, de la présence d'une petite nécropole à incinération de La Tène C2-D1, et d'un contexte topographique et géographique (accès au massif jurassien par la haute vallée du Doubs, ouverture sur la plaine d'Alsace et la vallée du Rhin) extrêmement favorable au développement d'un habitat groupé laténien (fig. 80). À l'époque antique, Mandeure est la deuxième ville de Séquanie, derrière la capitale de cité, par son extension et sa parure monumentale. Le sanctuaire se trouve alors intégré dans un complexe monumental, où il est associé à un théâtre et à d'autres édifices (thermes ou temples) dont la présence a été décelée tout récemment, par prospection magnétique. Les découvertes de matériel laténien ont été réalisées au cours de fouilles sauvages, dans les deux dernières décennies $d u X X^{e} \mathrm{~s}$. Les objets se trouvaient sous le temple de type gréco-romain, sous une épaisse couche de graviers que l'on peut probablement mettre en relation avec l'aménagement du sanctuaire antique. Ils ont été exhumés en une fois, par une excavation d'une dizaine de mètres carrés et de $2 \mathrm{~m}$ de profondeur. Cet ensemble se distingue par sa variété et par l'abondance de certaines séries. La catégorie de loin la plus importante correspond aux perles annulaires et bracelets en verre, au nombre de 541 (Guillard, 1989). L'armement et la panoplie de guerrier sont illustrés par un haut d'épée avec fourreau, un fer de lance, une quinzaine d'agrafes de ceinturon et plusieurs talons de lance. Une trentaine de fibules en bronze apparentées au type de Nauheim, deux autres en argent et deux fibules en fer de schéma La Tène moyenne ont été recensées, ainsi qu'une cinquantaine d'anneaux en fer, bronze et schiste. Deux éléments de joug de char à pattes de fixation décorées de palmettes et tige moulurée surmontée d'un cabochon émaillé figurent également dans cet ensemble, ainsi qu'un lot de six vases miniatures très proches, dans leurs formes et leur facture, d'exemplaires retrouvés à Mirebeau-sur-Bèze. Deux groupes d'objets sortent clairement de l'ordinaire, en premier lieu trois fragments de tôle de bronze appartenant, semble-t-il, à

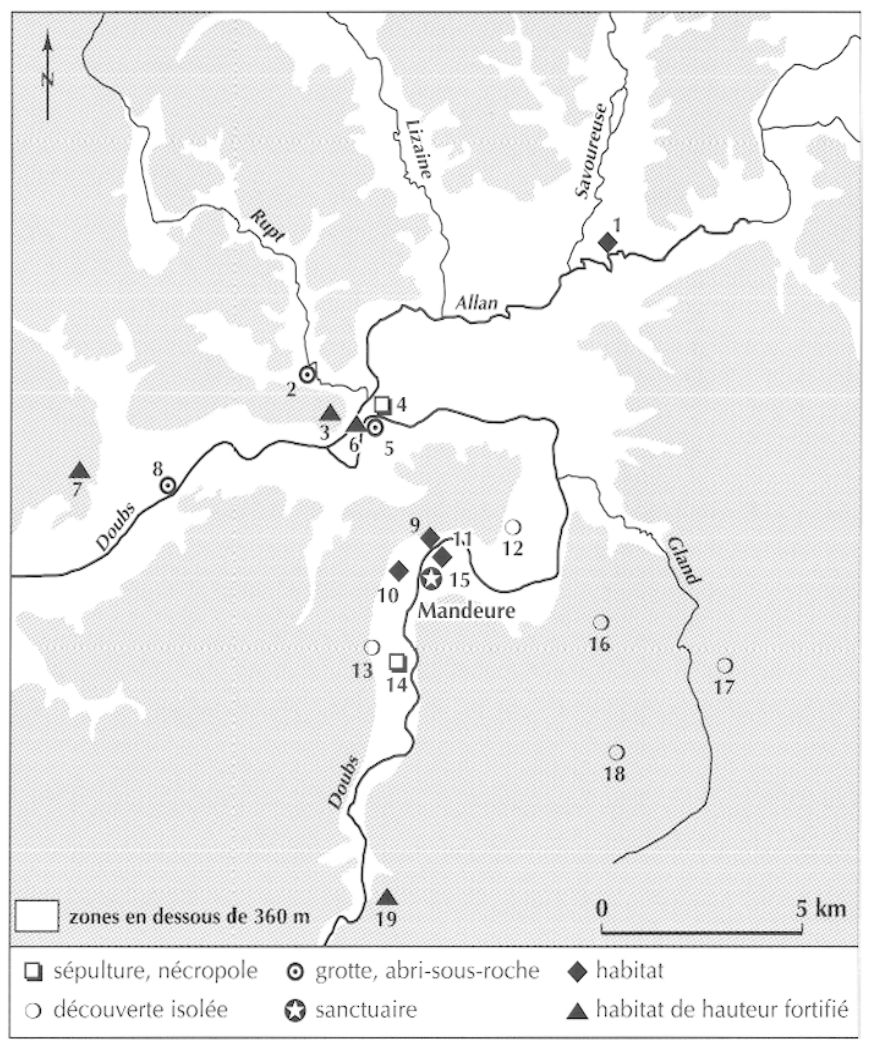

Fig. 80 - Le sanctuaire de Mandeure (Doubs) dans son contexte territorial de La Tène finale: 1, Les Prés Haiches à Étupes; 2, Sainte-Suzanne; 3, Monl Barl à Bavans; 4, Aux Carrons à Bart ; 5, abris du Chataillon à Bart ; 6, Camp de Chataillon à Bart ; 7, Le Giémont à Lougres; 8, Sous Roche à Bavans ; 9, SaintSymphorien à Mathay; 10, Champ des Isles à Mathay; 11, La Boucle à Mandeure ; 12, Pézole à Valentigney; 13, Romont à Mathay ; 14, Les Longues Raies à Mathay; 15, Clos du Château à Mandeure; 16, Le Haut des Bois à Bondeval; 17, La Bouloie à Hérimoncourt ; 18, La Croisée à Blamont ; 19, Mont-Julien à Pont-de-Roide (DAO P. Barral, CNRS).

au moins deux pavillons de carnyx, en second lieu un ensemble de six feuilles stylisées à tige creuse en bronze, que l'on peut rapprocher d'exemplaires identiques trouvés sur le site de La Tène, en Suisse (Pichot, 1996). Chronologiquement, la très grande majorité de cet ensemble appartient à La Tène C2-D1, quelques pièces semblant se rattacher à La Tène Cl. La composition de cet ensemble fait indéniablement penser à un dépôt de type favissa.

Bibliographie : Guillard, 1989 ; Pichot, 1996.

P. BARRAL 


\section{NOTICE 14}

\section{MARNAY (HAUTE-SAÔNE)}

\section{ÎLES DE MARNAY}

Lc giscment des Îles de Marnay est situé sur un affluent de la Saône, l'Ognon. Occupé dès le Néolithique, ce secteur constitua dès la Protohistoire un carrefour de voies terrestres liées à la présence de plusieurs gués, rôle maintenu durant l'Antiquité par un croisement de voies romaines et la construction d'un pont romain. Des objets datables du Néolithique à l'époque moderne ont été recueillis en très grand nombre: ossements animaux, métal, céramique. Cette concentration d'objets dans le lit de la rivière est probablement de nature cultuelle, par analogie avec d'autres découvertes de même type. Pour ce qui concerne le second âge du Fer (La Tène D), on constate la présence d'armes, précisément d'un fer et de deux talons de lance, et d'outils: quatre haches à douille en fer. La céramique comprend des amphores Dressel 1 et de la céramique indigène (Monnet, Thévenin, 1983).

Bibliographie : Monnet, Thévenin, 1983.

P. BARRAL

\section{NOTICE 15}

\section{MIREBEAU-SUR-BÈZE (CÔTE-D'OR)}

\section{La Fenotte}

Cette agglomération gallo-romaine située sur le cours de la Bèze, affluent de la Saône, et sur la grande voie de Chalon-sur-Saône à Langres possède un sanctuaire, comprenant deux temples de type fanum et un certain nombre d'autres édifices annexes, ainsi qu'une forteresse militaire. Le site se trouve dans la partie méridionale de la cité lingonne (à peu de distance des territoires des Éduens et des Séquanes, dont les frontières convergeaient dans le secteur dijonnais) sur un axe de communication nord-sud, probablement préromain (cf. prospection aérienne).

Le sanctuaire augustéen est installé sur un lieu de culte gaulois.

- Une enceinte ovale fossoyée (fossé ouvert), fondée dans la première moitié du $\mathrm{III}^{\mathrm{e}} \mathrm{s}$. avant J.-C. (La Tène B2-Cla), constitue le sanctuaire primitif, situé à l'ouest des fana. À cette phase appartiennent un dépôt de fibules en bronze mis au jour dans le comblement du fossé et divers mobiliers (céramiques, armes), généralement retrouvés en association avec du matériel plus récent de La Tène $\mathrm{D}$, dans des niveaux de destruction et des fosses. Le fossé de l'enceinte a été palissadé alors qu'il était presque comblé.

- Des palissades, qui, pour certaines, réutilisent des portions du tracé du fossé du $11 I^{\mathrm{e}} \mathrm{s}$. avant $\mathrm{J}$.-C., sont attribuables à un état du sanctuaire daté de La Tène C2-D1a. De nombreux dépôts en fosse sont situés dans le futur secteur des fana. La céramique et la faune prédominent, complétées par de la parure (bracelets en bronze, fibules en fer et bronze, perles et bracelets en verre), de l'outillage, des pièces d'armement et parfois des monnaies (fig. 81). Les pièces métalliques présentent fréquemment des traces de bris volontaire.

- À la fin de La Tène D2, la zone du sanctuaire est intégrée dans l'angle d'une très vaste enceinte, dont deux branches, d'une centaine de mètres de longueur, se rejoignant à angle droit ont été reconnues récemment. Cette enceinte est matérialisée par trois (voire quatre) fossés parallèles, larges de 4 à $5 \mathrm{~m}$, alors que dans un angle, une entrée fortifiée avec porterie (deux états successifs) a été identifiée. Cette enceinte au caractère militaire affirmé, englobant le sanctuaire, lui est-elle strictement et exclusivement liée, ou bien intègre-t-elle d'autres secteurs d'occupation, non découverts à ce jour ? À cette phase semblent correspondre des fosses à dépôts d'ossements de grands herbivores (surtout). D'autres fosses de La Tène D2 évoluée associent de la faune et de la céramique de palissades de la période antérieure. Deux bâtiments à poteaux et des enclos palissadés, fonctionnant chronologiqucment avcc ces dépôts, ont été mis au jour en 2002.

Le sanctuaire a donc été fondé dans la première moitié du III ${ }^{c}$ s. avant J.-C. et a fonctionné sans interruption jusqu'à l'époque augustéenne. La phase la moins bien attestée correspond à la transition La Tène D1-D2. Trois étapes de construction/aménagement sont pour l'instant identifiées : première moitié $d u \mathrm{III}^{\mathrm{c}} \mathrm{s}$. avant J.-C., milieu du II $\mathrm{e}$. avant J.-C. et milicu du I ${ }^{\text {er }}$ s. avant J.-C. Enfin, l'évolution dans la composition des dépôts mobiliers est nettement perceptible entre les différentes phases du sanctuaire gaulois.

Bibliographie : Brunaux et al., 1985; Guillaumet, Barral, 1991 ; Barral et al., 2002 ; Barral, Guillaumet, Nouvel, 2002.

P. BARRAL

\section{NOTICE 16}

\section{NITRY (YONNE)}

\section{Champagne}

Le site de Champagne à Nitry cst implanté sur les plateaux calcaires de basse Bourgogne, dans une petite plaine circulaire entourée au sud et à l'ouest par une 

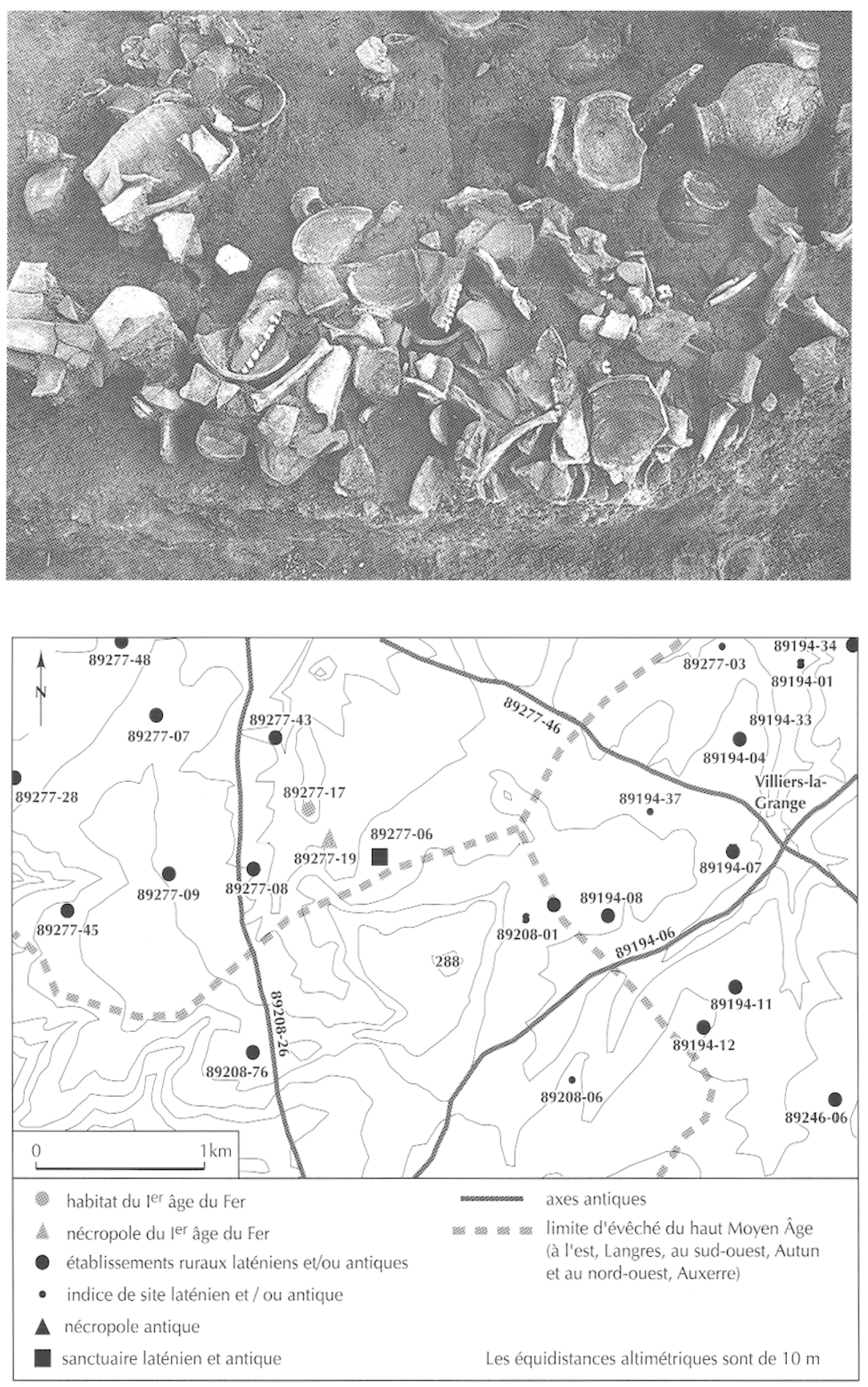

Fig. 81 - Mirebeau-sur-Bèze (Côte-d'Or). Sanctuaire de La Fenotte : dépôt mobilier (vases céramiques, faune) daté de 140-110 avant J.-C. (photo P. Barral, CNRS).
Fig. 82 - Nitry (Yonne). Plan des structures de l'âge du Fer en Champagne (DAO P. Nouvel). couronne de buttes d'une cinquantaine de mètres de hauteur (fig. 82). Il se trouve au centre d'un triangle formé par le croisement de trois axes secondaires antiques. Ce territoire est l'un des mieux connus du département car il a fait l'objet de prospections aériennes et terrestres quasi systématiques (Poitout el al., 2001, p. 54-55).
D'une superficie de $850 \mathrm{~m}^{2}$, la fouille a permis l'étude de la totalité du site. La phase la plus ancienne voit la mise en place d'une série de fosses oblongues, orientées est-ouest, qui ont reçu, pour certaines, des dépôts de céramique ou d'objets métalliques datés de La Tène C2. Par la suite, vers le milieu du $\mathrm{II}^{\mathrm{e}} \mathrm{s}$. avant J.-G., un fossé de $20 \mathrm{~m}$ de côté est 
creusé, ouvert à l'est, doublé d'une ligne de poteaux externes. Au centre, un second enclos, neuf fois plus petit mais de même module, contient un bâtiment supporté par quatre poteaux. Au cours de la seconde moitié du $\mathrm{II}^{\mathrm{e}} \mathrm{s}$. et durant le $\mathrm{I}^{\mathrm{er}}$ s. avant J.-C., le bâtiment central connaît deux phases de réaménagements alors que les fossés se comblent progressivement par un apport d'éléments osseux, céramiques et métalliques issus de dépôts secondaires. Dans la seconde moitié du $I^{\text {er }}$ s. avant J.-C., un bâtiment annexe est élevé au nord-ouest de l'édifice central et une fosse, creusée au sud-est, reçoit un dépôt primaire constitué d'épaules de porcs, de meules, de deux céramiques et d'une faucille. Ce lieu de culte sera fréquenté jusqu'à la fin de l'Antiquité.

Le matériel recueilli dans les couches laténiennes consiste en céramiques (très peu d'amphores), en éléments osseux (essentiellement ovins et porcins), en quelques éléments métalliques, essentiellement de la parure (bracelets en bronze et fibules en fer) et du numéraire presque exclusivement en frappes issues de l'orbite éduenne (potins LT 2935, LT 4628, grosse tête G.T. 8.1, bronzcs LT 5086), et en une série de potins locaux nommés "tête de chou-fleur " dont les lieux de découverte se concentrent sur le territoire de la future cité auxerroise (Barral, Guillaumet, Nouvel, 2002). Ce faciès majoritaire souligne l'appartenance de cette zone à l'orbite éduenne au dernier siècle avant J.-C.

Le site de Nitry est donc un cxcmplc intćrcssant dc pctit sanctuaire rural éduen dont le statut modeste est souligné par le caractère peu luxueux du mobilier recueilli.

Bibliographie : Poitout et al., 2001; Barral, Guillaumet, Nouvel, 2002.

P. NOUVEL

\section{NOTICE 17}

\section{NUITS-SAINT-GEORGES (CÔTE-D'OR)}

\section{LES BOLARDS}

Située dans la plaine dijonnaise sur le cours du Meuzin, un affluent de la Saône, l'agglomération gallo-romaine des Bolards aux confins du territoire éduen a été fouillée dans les années 1960-1980 (Barral, Guillaumet, 2001). Une zone d'habitat a livré des indices d'occupation de La Tène D2 et de l'époque augustéenne. Un sanctuaire gallo-romain a été édifié sur un sanctuaire préromain dont les vestiges n'ont été reconnus que très ponctuellement. Deux temples de type fanum, dont le second est attribué à l'époque augustéenne, ont été mis en évidence. Du matériel de La Tène finale provient par ailleurs de couches profondes, sondées localement, et de remblais gallo-romains : céramique indigène, amphores Dressel 1, monnaies et parures: bracelet tubulaire en bronze de La Tène D1, bracelets filiformes en bronze, à extrémités spiralées ou se chevauchant, fibules. Ce matériel n'est pas antérieur à La Tène D1 et couvre toute La Tène finale. Rattachée au premier fanum dont ne subsistaient qu'une partie du péribole et un sol en terre battue, une fosse a livré un ensemble mobilier homogène de La Tène $\mathrm{D} 1$, vraisemblablement de fonction votive ou cultuelle : des vases céramiques (107 individus), en majorité entiers, quoique brisés, qui ont subi l'action du feu et des petits fragments d'amphores Dressel 1 suggérant un bris volontaire. Un type de vase prédomine nettement (80 ind.) : bouteille à pâte claire, parfois décorée sommairement de bandes de couleur sur le col et l'épaule (Barral, Guillaumet, 2001).

Bibliographie : Barral, Guillaumet, 2001.

P. BARRAL

\section{NOTICE 18}

\section{ORCINES (PUY-DE-DÔME)}

Le grand sanctuaire de Mercure au sommet du puy de Dôme est surtout connu pour les imposants monuments romains qu'il héberge à près de $1500 \mathrm{~m}$ d'altitude: un système de terrasses et d'escaliers supportant un temple de type gréco-romain et des bâtiments annexes occupés du règne d'Auguste au haut Moyen Âge. Le site a longtemps été identifié, à tort, à celui de la statue colossale en bronze, sculptée selon Pline par Zénodore, en l'honneur de Mercure Dumias. De même, une fréquentation antérieure du site "à l'époque de La Tène " est évoquée sur la foi de trouvailles du XIX s., imprécisément datées.

Les niveaux correspondant à ce premier horizon font encore défaut. Si l'existence d'une activité cultuelle antérieure à l'époque romaine semble être effectivement confirmée par le réexamen du mobilier (voir infra), il est impossible d'en estimer l'ampleur ou la nature, la présence d'un site d'habitat étant peu plausible à une telle altitude.

Certaines catégories d'objets ne plaident pas pour une fréquentation très ancienne du site. Leur sélection ou les traitements dont elles sont l'objet trahissent leur implication dans une activité rituelle de type indigène. Les armes d'hast occupent de loin la première place: plusieurs dizaines de fers de lance. Deux découvertes effectuées aux abords des temples évoquent des lots groupés. À la même période se rattachent plusieurs lames d'épée avec des marques de détériorations volontaires. La découverte de pièces d'arme.ment mutilées sur le sanctuaire du puy de Corent (voir infra 
notice 22, p. 164-165) montre que ces pratiques avaient encore cours sur le territoire arverne au I $^{\text {er }}$ s. avant J.-C. Beaucoup de ces armes ont aujourd'hui disparu ou sont dispersées dans les collections nationales. Leur nombre est inhabituel pour l'époque gallo-romaine où ce type d'offrandes marque généralement un net recul par rapport à la période gauloise. Un «torque à tampons » en bronze, ainsi que quelques fibules gauloises comptent également parmi les offrandes caractéristiques des sanctuaires de cette période. Enfin se rattachent au même horizon quelques céramiques laténiennes. La rareté du monnayage gaulois (deux potins et une dizaine de bronzes frappés d'origine régionale) comparativement aux monnaies romaines et aux autres sites laténiens de la région peut, en revanche, être considérée comme significative. Parmi les céramiques prédominent les amphores républicaines avec plus d'une dizaine d'individus. Leur présence n'est nullement anodine, puisqu'il est établi par les fouilles récentes que le vin et son emballage jouaient un rôle prépondérant dans les pratiques religieuses des Arvernes (voir notices 7 et 22).

La typologie des amphores (Dressel 1A et 1B) et des fibules (filiforme, à ailettes et à collerette) est surtout caractéristique de la dernière phase de l'époque laténienne. Elle documente surtout un premier état de fondation du sanctuaire romain à $\mathrm{La}$ Tène $\mathrm{D} 2$. Celle des armes renvoie, en revanche, à La Tène $\mathrm{B}$. Le lien de continuité entre les deux faciès semble assuré par deux fibules en fer attribuablcs à La Tène moyenne (musée Bargoin). La coïncidence plaide, quoi qu'il en soit, pour une continuité fonctionnelle. Il correspondrait dans cette hypothèse au plus ancien lieu de culte connu sur le département du Puy-de-Dôme, contemporain de l'horizon des grands sanctuaires du Belgium. Une fréquentation épisodique des lieux, pour des offrandes ponctuelles amassées à des emplacements plus ou moins aménagés (autels, " chapelles " ou rochers naturels), est envisageable.

Bibliographie : Casas, 1994.

M. Poux

\section{NOTICE 19}

\section{ORMOY (YONNE)}

\section{SOUVILLE}

Récemment découvert en prospection terrestre, ce site de vallée alluviale est implanté sur les premières pentes du coteau dominant au sud la vallée de l'Armançon, non loin de son confluent avec l'Yonne, de part et d'autre d'une petite source. Une voie secondaire reliant les agglomé- rations d'Avrolles (Eburobriga), au nord-est, et de Bassou (Bonoritum), au sud-est, le longe au nord. Grâce aux prospections terrestres, deux bâtiments quadrangulaires à sols mosaĩqués ont été reconnus, à proximitë desquels s'observaient des concentrations de monnaies gauloises. Les prospections aériennes ne permettent pas d'en préciser l'organisation interne mais indiquent la présence de fossés, de greniers sur poteaux et de fosses qui confirment l'existence d'un établissement laténien antérieur.

Le matériel céramique recueilli atteste une fréquentation depuis La Tène D2a au moins jusqu'au haut Moyen Âge. Les éléments métalliques datables de l'époque laténienne consistent en un fragment de passe-guide à tête moulurée et excisée, ornée d'inclusions colorées, en fibules, en différents éléments métalliques qui n'ont pas encore été étudiés et en 18 monnaies: 1 statère uniface inédit, 2 bronzes gaulois LT 7493, 3 potins LT 7417, 10 quinaires gaulois et enfin 2 deniers consulaires.

Bibliographie : Delor dir., 2002.

P. Nouvel.

\section{NOTICE 20}

\section{SENAN (YONNE)}

\section{PoIrIER Bourgeois}

$\mathrm{Au}$ cœur d'une agglomération rurale implantée en rive droite du Tholon, non loin de son confluent avec l'Yonne, la concentration sur un gros bâtiment de nombreuses tuiles engobées, de blocs architecturaux, de marbres, de monnaies gauloises et de nombreuses monnaies tardives permet d'envisager un lieu de culte, distant de moins de $100 \mathrm{~m}$ à l'est du seul théâtre antique actuellement connu dans l'Yonne. Céramiques non tournées et tournées, grossières, micacées, tessons d'amphores Dressel 1, deux potins LT 7496, six potins LT 7417 et un de la série à « tête diabolique » sont inédits.

P. NOUVEL

\section{VERDUN-SUR-LE-DOUBS (SAÔNE-ET-LOIRE)}

\section{Le Petit-Chauvort}

C'est un habitat groupé d'une surface de 10 ha environ ; quelques documents attestent son occupation précoce mais limitée dès La Tène B2. Localisé sur la rive gauche de la 


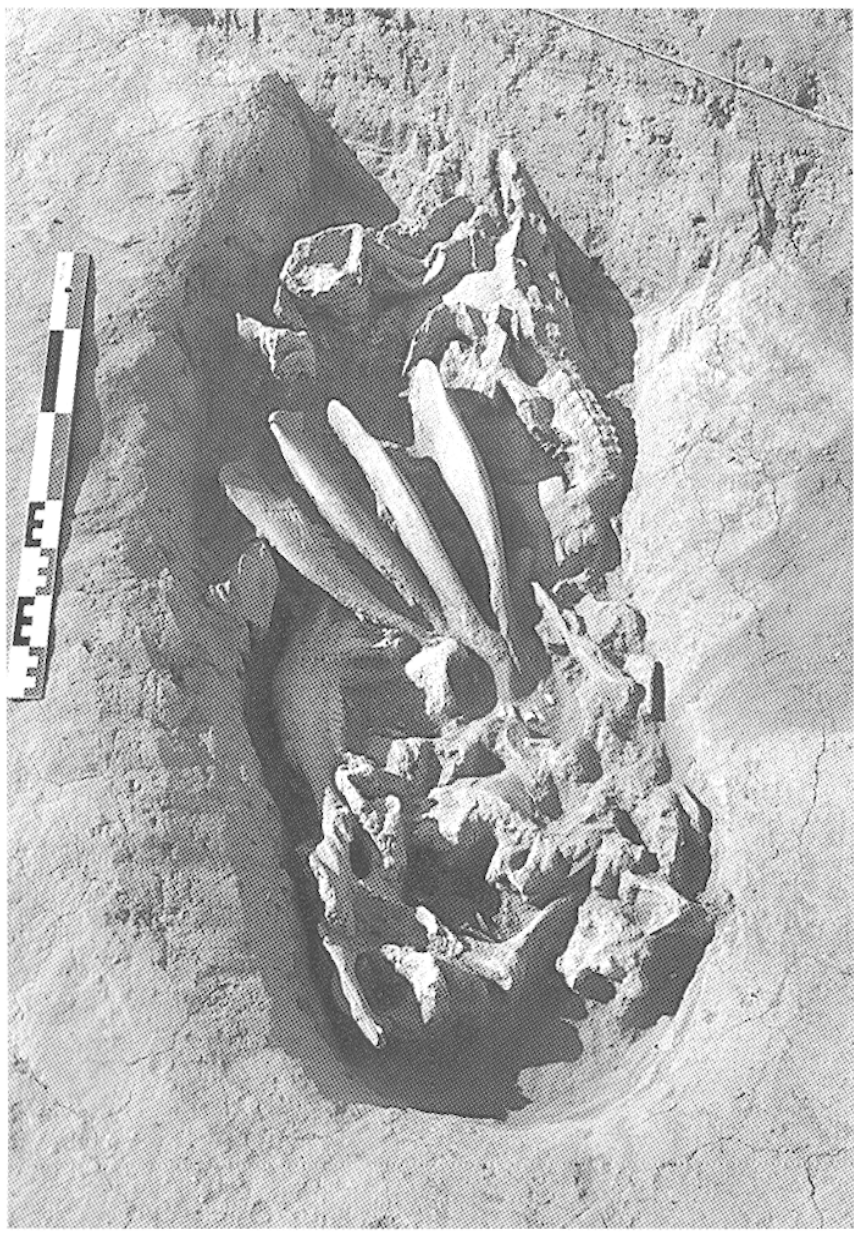

Fig. 83 - Verdun-sur-le-Doubs (Saône-et-Loire).

Habitat du Petit-Chauvort : dépôt d'ossements animaux organisé en fosse, daté du II s. avant J.-C. (photo P. Barral, CNRS).

Saône, à proximité de plusieurs passages à gué, cet habitat est lié à un pôle d'occupation de la confluence DoubsSaône-Dheune. Les vestiges de pratiques cultuelles se limitent à une structure isolée en bordure de voie : petite fosse ovale, de $1 \mathrm{~m}$ de long environ, sur $0,40 \mathrm{~m}$ de large, profonde de $0,30 \mathrm{~m}$, aménagée dans le substrat, comblée exclusivement d'ossements animaux (éléments de crâne, rachis, mâchoires de grands herbivores: bơuf, cheval) (fig. 83). Cette structure se distingue des fosses à rebuts détritiques habituelles sur ce site. On signalera en particulier l'absence de céramique et autre objet manufacturé, ainsi que le caractère très organisé du remplissage (ossements disposés et non jetés, non fragmentés) qui caractérise un dépôt volontaire. La situation topographique de cet aménagement autorise une datation dans le courant de La Tène C2-D1a (Barral, 1999; Barral, Beuret et al., 2001). Cette structure peut être rapprochée assez précisément d'un fossé d'Yverdon-les-Bains (Suisse) qui a livré un nombre anormal de mandibules de bovidés (Brunetti, 2001).

Bibliographie: Barral, 1999; Barral, Beuret et al., 2001 ; Brunetti, 2001.

\section{P. BARRAL}

\section{NOTICE 22}

\section{VEYRE-MONTON (PUY-DE-DÔME)}

\section{Puy de Corent}

Ce vaste oppidum, établi sur le plateau volcanique du puy de Corent, à une trentaine de kilomètres au sud-est de Clermont-Ferrand a été occupé du Néolithique à la fin de l'époque romaine. Les centaines d'amphores républicaines et de monnaies gauloises, en partie frappées sur place (trois coins monétaires), font de ce site l'oppidum principal de la cité arverne au début du $\mathrm{I}^{\text {er }}$ s. avant J.-C.

Le sanctuaire indigène se signale à l'époque romaine par un péribole quadrangulaire d'environ $70 \mathrm{~m}$ de côté ; fréquenté de la fin du II ${ }^{e}$ s. avant J.-C. à la fin du III ${ }^{e}$ s. après J.-C., il succède à une occupation de la Protohistoire ancienne. Un premier noyau cultuel d'époque gauloise est matérialisé par des tronçons de fossés parallèles intégrés à un système d'enclos et de vastes aires de circulation qui recelaient un très abondant mobilier céramique, osseux (rares os humains : demi-frontal féminin) et métallique (garnitures de boucliers en fer mutilées: umbos présentant des traces de percussion, orles ployées). La principale caractéristique de ce sanctuaire réside, cependant, dans la masse considérable d'amphores vinaires et de têtes de bétail qui se chiffre, dans les deux cas, à plusieurs centaines d'individus, soit plus de $90 \%$ du mobilier. Ces vestiges correspondent moins à des offrandes qu'à des reliefs alimentaires consommés lors de festins cultuels, assortis de sacrifices et de libations: préférence marquée pour les ovicaprinés, abattus et consommés par dizaines, tri et rejet des parties non consommables dans les fossés (crânes, mandibules, pieds), décolletage et bris intentionnel des amphores à coups de lame. Les fouilles récentes ont permis de préciser l'organisation interne et la chronologie du sanctuaire.

Le centre géographique et fonctionnel consiste en un enclos rectangulaire d'environ $10 \mathrm{~m}$ sur $8 \mathrm{~m}$ : des alignements de blocs de basalte, des clous, agrafes et éléments de charpente en fer, marquent la trace de cloisons ou palissades en bois. Ces alignements étaient doublés, sur leur face interne, d'un petit fossé à profil en cuvette, comblé d'offrandes diverses. Au milieu de la façade nord, un porche d'entrée monumental sur deux poteaux. L'intérieur de 
l'enclos était vide de tout aménagement excepté une grande fosse creusée à gauche de l'entrée (" autel creux " ?) et un gros monolithe de basalte (pierre d'autel ?) disposé dans le même axe, contre la paroi faisant face à l'entrée. Le plan de l'enclos et ses aménagements internes présentent de très fortes similitudes avec le petit édifice du Brézet, sanctuaire de Clermont-Ferrand (voir supra notice 7, p. 153-154). Au nord, de part et d'autre de l'entrée, ont été édifiés deux petits bâtiments rectangulaires d'environ $4 \mathrm{~m}$ sur $2 \mathrm{~m}$ abritant des activités culinaires. En périphérie se trouvent des centaines de tessons d'amphores Dressel 1A et 1B, et des restes animaux, triés, puis regroupés dans certaines portions du fossé. Des amphores ont subi un décolletage par lame et/ou un bris volontaire à l'aide de grosses pierres, faisant penser que leur contenu a été déversé en guise de libation. Les vaisselles se distinguent également par leur qualité : formes complètes déposées sur le pendage du fossé (jattes, imitations de campaniennes et formes hautes), anses et garnitures en fer de chaudron, seau et situle, coupe en verre taillé originaire d'Orient (Syrie ?), campanienne B, dont une coupe au fond percé réaménagée en récipient libatoire. L'armement occupe une place non négligeable : fragments de gouttières, barrettes et plaque de fourreau d'épée et de glaive, deux fers et trois talons de lance miniature. La dissociation des armes offensives (armes de taille et d'hast déposées dans les fossés d'enclos, éléments de boucliers relégués à la périphérie), comme les torsions ou percussions volontaires dont elles témoignent sont caractéristiques d'un rite surtout attesté, jusqu'à présent, en Gaule belgique et atlantique. La parure se distingue également, avec de nombreuses fibules en bronze et en fer (une quinzaine d'exemplaires type Nauheim ou dérivés pratiquement identiques et de très petit module) et plusieurs dizaines d'anneaux en bronze ou en os de module variable, ces derniers produits sur place. Enfin, d'autres catégories d'objets occupent une place plus marginale: pendant de mors, outils en fer, vestiges de tabletterie.

Le sanctuaire ou ses abords immédiats ont abrité une intense activité monétaire: plus d'une centaine de monnaies en argent et en bronze (forte prépondérance, au sein des offrandes, d'autres monnayages spécifiques au plateau de Corent ; monnaies « au renard " LT 3955), puis, un nombre équivalent de jetons céramiques (substituts d'offrandes monétaires ?) et lors de prospections effectuées au-delà de la limite orientale du téménos, trois coins de frappe portant sur des numéraires en usage dans la première moitié du $\mathrm{I}^{\mathrm{er}} \mathrm{s}$. avant J.-C. Contrairement à ce qui a été soutenu, la fréquentation du sanctuaire de Corent ne semble pas avoir continué après une brève période, limitée à une génération seulement (premier quart du ${ }^{\text {er }} \mathrm{s}$. avant. J.-C.). L'analyse stratigraphique des fossés et la définition de plusieurs ensembles clos de datation légèrement décalée montrent que plusieurs repas se sont succédé à proximité de l'enclos. Le comblement des fossés comporte au moins trois phases de remplissage. Le mobilier recueilli à leur base (jatte d'Aulnat, fibule de Nauheim), allié à d'autres indices périphériques (fibule de $\mathrm{La}$ Tène $\mathrm{C} 2$, bracelet en verre côtelé bleu à filaments jaunes), situe leur creusement dans le dernier tiers du $\mathrm{II}^{\mathrm{c}} \mathrm{s}$. avant J.-C. Après une activité maximale à La Tène $\mathrm{D} 1 \mathrm{~b}$ et $\mathrm{D} 2 \mathrm{a}$, l'enclos est démantelé et ses fossés remblayés peu avant le milieu du I ${ }^{\text {cr }}$ s. avant J.-C. Son plan sera néanmoins repris au mètre près, à l'époque romaine, par un bâtiment maçonné de fonction probablement identique, fréquenté au moins jusqu'à la fin du $\mathrm{III}^{\mathrm{e}} \mathrm{s}$. après J.-C.

Le sol en terre battue placé sous la protection symbolique de l'enclos (temenos) a néanmoins été épargné à chaque réaménagement du sanctuaire, permettant la fossilisation des niveaux préhistoriques sous-jacents.

Bibliographie : Guichard, Collis, 1992 ; Provost, MennessierJouannet, 1994 ; Poux, 2001, 2002.

M. Poux

\section{NOTICE 23}

\section{VIENNE (ISÈRE)}

\section{SAINTE-BLANDINE}

Vienna, capitale du peuple allobroge (Strabon, Géographie, IV, 1, 11) occupe une position excentrée au bord $\mathrm{du}$ Rhône, à la frontière ouest du territoire. Elle est entourée de cinq collines disposées en hémicycle : les monts Salomon, Arnaud, Pipet, Saint-Just et la colline SainteBlandine. Les recherches menées depuis les années 1960 ont permis d'identifier les témoins d'une occupation ininterrompue depuis le $\mathrm{V}^{\mathrm{e}} \mathrm{s}$. avant J.-C. L'habitat s'est développé rive gauche, sur un éperon rocheux dominant le confluent du Rhône et de la Gère, et s'est vraisemblablement fixé le long d'un ensellement nord-sud traversant ce promontoire. À partir du $\mathrm{II}^{\mathrm{e}}$ s. avant J.-C. l'agglomération va s'étendre grâce à la libération progressive des zones inondables consécutive au changement de régime du fleuve (fig. 84).

La colline Sainte-Blandine, située en arrière du mont Pipet, a fait l'objet de plusieurs découvertes depuis le XIX ${ }^{e} \mathbf{s}$. De 1895 à 1898, les premières interventions, mal localisées ont livré quelques objets et monnaies relatifs au passé préaugustéen de la cité. En 1955, lors de l'aménagement d'un chemin d'accès privé creusé dans un remblai accolé à un double mur (dont l'un appartient à l'enceinte augus- 


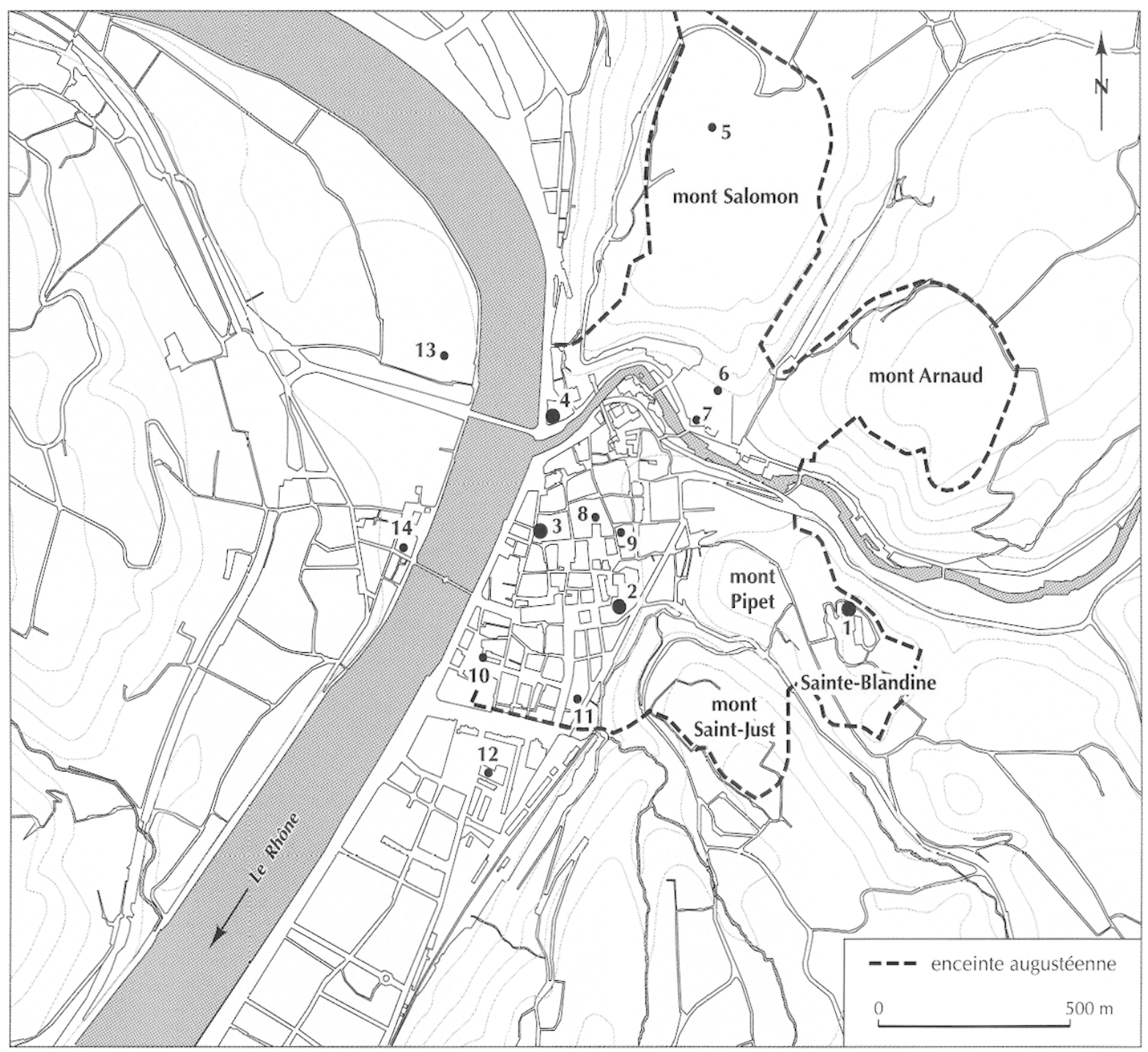

Fig. 84 - Carte de répartition des découvertes de l'âge du Fer à Vienne (Isère) : 1, dépôt métallique de Sainte-Blandine; 2, Jardins de Cybèle; 3, rue de Bourgogne ; 4, Notre-Dame-d'Outre-Gère ; 5, hôpital Lucien-Hussel ; 6, rue des Colonnes ; 7, église Saint-Martin ; 8, hôtel de Ville ; 9, rue des Orfêres ; 10, place Saint-Pierre; 11, banque de France; 12, place Camille-Jouffray; 13, site archéologique de Saint-Romain-en-Gal; 14, Sainte-Colombe, rue Paul-Doumer (DAO V. Durand, musée de Vienne).

téenne), fut mis au jour un amas d'objets compactés sur une dizaine de mètres de longueur et $2 \mathrm{~m}$ de hauteur ${ }^{9}$. À la suite de cette découverte, un sondage révéla la présence, au sommet de la colline, d'un bâtiment romain à dallage d'éléments en pierre de taille grossière, peut-être un sanctuaire. Dans les années 1970, un sanctuaire gallo-romain à triple cella (capitole ?) fut dégagé en contrebas du dépôt ;

9. Le mobilier découvert a fait l'objet d'une donation et est actuellement conservé au musée des Reaux-Arts et d'Archéologic de Vienne (Isère). dans le mobilier figuraient quelques céramiques campaniennes $\mathrm{A}$ et $\mathrm{B}$.

Malgré le caractère fortuit de cette découverte, l'intervention immédiate de $\mathrm{G}$. Chapotat permit un ramassage systématique du matériel tant métallique que céramique. Cet ensemble, daté essentiellement de La Tène $\mathrm{Dl}{ }^{10}$, s'avère relativement riche tant par la quantité des objets

10. Plusieurs fibules du type pseudo-la Tène II datent cependant du principat d'Auguste et de Tibère. 

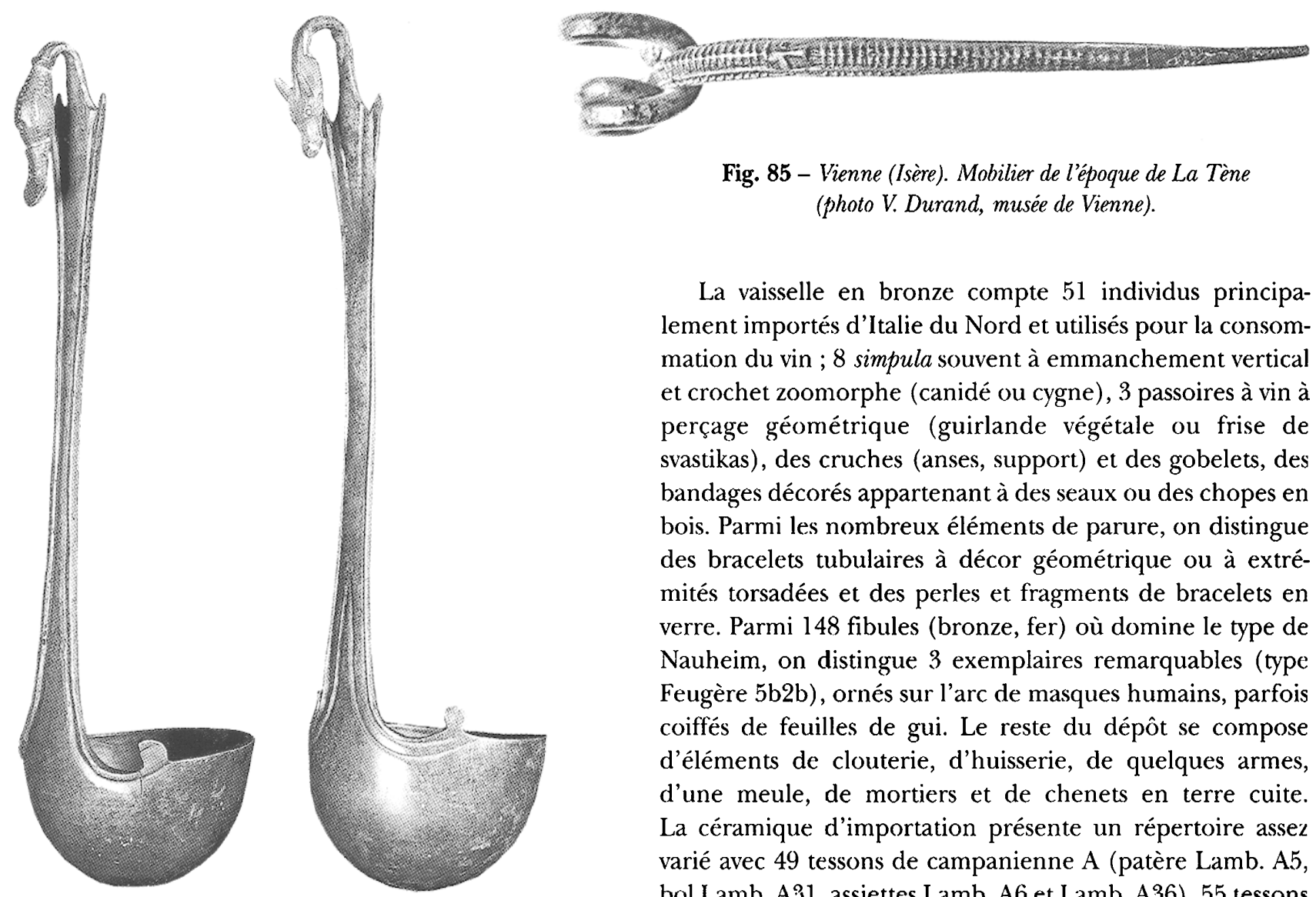

Fig. 85 - Vienne (Isère). Mobilier de l'époque de La Tène (photo V. Durand, musée de Vienne).

La vaisselle en bronze compte 51 individus principalement importés d'Italie du Nord et utilisés pour la consommation du vin ; 8 simpula souvent à emmanchement vertical et crochet zoomorphe (canidé ou cygne), 3 passoires à vin à perçage géométrique (guirlande végétale ou frise de svastikas), des cruches (anses, support) et des gobelets, des bandages décorés appartenant à des seaux ou des chopes en bois. Parmi les nombreux éléments de parure, on distingue des bracelets tubulaires à décor géométrique ou à extrémités torsadées et des perles et fragments de bracelets en verre. Parmi 148 fibules (bronze, fer) où domine le type de Nauheim, on distingue 3 exemplaires remarquables (type Feugère 5b2b), ornés sur l'arc de masques humains, parfois coiffés de feuilles de gui. Le reste du dépôt se compose d'éléments de clouterie, d'huisserie, de quelques armes, d'une meule, de mortiers et de chenets en terre cuite. La céramique d'importation présente un répertoire assez varié avec 49 tessons de campanienne A (patère Lamb. A5, bol Lamb. A31, assiettes Lamb. A6 et Lamb. A36), 55 tessons de campanienne B (assiettes Lamb. B5, coupes Lamb. B1, assiettes Lamb. B6, pyxides Lamb. B3, vases ansés Lamb. B10), et 2 fragments de campanienne C. Les amphores italiques sont très peu représentées ( 9 fragments). En ce qui concerne la céramique indigène, la vaisselle tournée, grise, fine, à surface lissée, est majoritaire : plats, jattes, assiettes (décor ondé). La céramique peinte s'illustre dans une proportion réduite par des formes hautes et fermées à bandes blanches et rouge-brun. La vaisselle non tournée compte principalement des écuelles à lèvre digitée à pâte micacée cuite en mode $\mathrm{B}$.

Le problème majeur reste la méconnaissance générale du site de Sainte-Blandine. L'hypothèse d'un dépotoir d'habitat paraît peu valide (quasi-absence de faune, faible usure des objets justifiant une mise au rebut). En revanche, plusieurs observations pourraient aller dans le sens d'un dépôt votif. Tout d'abord, la quantité de mobilier exhumé découvert, concentré sur une surface réduite (environ 900 objets métalliques et plus de 3500 fragments de céramique), s'avère énorme au regard de la surface explorée. Si la composition du lot, notamment du mobilier métallique, correspond assez bien à la culture des Oppida, quelques absences remarquables sont à noter: très peu d'armes, peu de monnaies, pas de chaudron mais une grande quantité de fourchettes. $\grave{A}$ 
l'opposé, certaines catégories sont très représentées : les composants du service à boire (vaisselle en bronze importée, céramique à vernis noir) et à manger (consommation de la viande sous diverses formes) sont particulièrement nombreux ainsi que les fibules. Si les objets complets sont nombreux, deux voire trois fibules semblent présenter des traces de torsion volontaire tendant à rendre l'objet inutilisable. La présence d'objets exceptionnels - trois fibules à masques humains, amulette à tête de dragon et quadrupède, anneau zoomorphe - conforte l'hypothèse d'un mobilier votif.

Bibliographie : Chapotat, 1970; Pelletier, 1976 et 2001, p. 91 ; Perrin, 1990 ; Durand, 2000 ; Perrin, Durand, 2002 ; Perrin, Schönfelder, 2003.

V. DURAND 